\title{
A new class of low surface energy anionic surfactant for enhanced oil recovery
}

\author{
Sajad Kiani, Sarah E. Rogers, Masanobu Sagisaka, \\ Shirin Alexander and Andrew R. Barron
}

\section{Published version information}

Citation: S Kiani et al. "A new class of low surface energy anionic surfactant for enhanced oil recovery." Energy \& Fuels, vol. 33, no. 4 (2019): 3162-3175.

DOI: $10.1021 /$ acs.energyfuels.9b00391

This document is the unedited author's version of a Submitted Work that was subsequently accepted for publication in Energy \& Fuels, copyright (C) American Chemical Society after peer review. To access the final edited and published work see DOI above.

Please cite only the published version using the reference above. This is the citation assigned by the publisher at the time of issuing the AAM. Please check the publisher's website for any updates. 


\section{A New Class of Low Surface Energy Anionic}

\section{Surfactant for Enhanced Oil Recovery (EOR)}

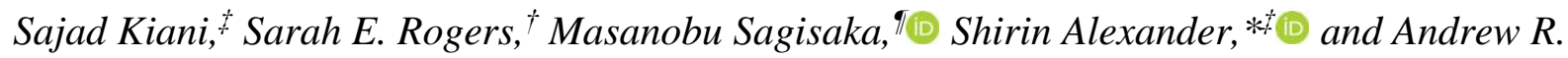

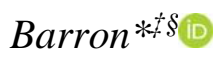

"Energy Safety Research Institute (ESRI), Swansea University, Bay Campus, Swansea SA1

8EN, UK. ISIS-STFC, Rutherford Appleton Laboratory, Chilton, Oxon OX11 0QX, UK.

"Department of Frontier Materials Chemistry, Graduate School of Science and Technology,

Hirosaki University, 3 Bunkyo-cho, Hirosaki, Aomori 036-8561, Japan. ${ }^{\S}$ Department of

Chemistry and Department of Materials Science and Nanoengineering, Rice University,

Houston, Texas 77005, USA.

ABSTRACT: A highly branched green low surface energy surfactant (LSES), stable in harsh conditions, was synthesized for enhanced oil recovery (EOR). Oil recovery factors were determined using a glass micromodel and indicated $72 \%$ increase in oil recovery in both low and high brine solutions, a remarkable result for only a single chain surfactant flooding. The surfaceinterface analysis of brine and brine-surfactant solutions were carried out, while small-angle neutron scattering measurements were used to determine the changes in surfactant structure in different brine solutions, and zeta potential experiments revealed the effect of monovalent and divalent cations in each solution. Adsorption analysis on crushed glasses was evaluated to see the maximum amount of surfactant adsorption in the system, and finally, oil recovery factors were discussed according to the interfacial tension and contact angle measurements. Based on our inclusive study we conclude that the cost-effective and environmentally friendly LSES present a class of potentially important material for use in various EOR scenarios, such as the low salinity, smart water, alkaline-surfactant-polymer, and nanoparticle-surfactant flooding. 


\section{INTRODUCTION}

Increasing oil transport through the pore and pore-throat channels lies at the center of all enhanced oil recovery (EOR) scenarios. ${ }^{1}$ Surfactant flooding is one of the most attractive methods in tertiary hydrocarbon recovery since the presence of surfactant reduces the interfacial tension between the oil and water phases and alters the wettability of the reservoir rock to improve oil recovery. There is a range of surfactant types (both natural and synthetic) that can be applied depending on the type of reservoir being treated, i.e., cationic, anionic, non-ionic, bio-surfactant, and zwitterionic. ${ }^{2-4}$ For EOR in sandstone reservoirs anionic surfactants are preferred with varying head groups: sulfonate $\left(\mathrm{R}-\mathrm{SO}_{3}{ }^{-}\right)$, phosphate $\left(\mathrm{R}-\mathrm{O}-\mathrm{PO}_{3}{ }^{2-}\right)$, sulfate $\left(\mathrm{R}-\mathrm{O}-\mathrm{SO}_{3}{ }^{-}\right)$, and carboxylate $(\mathrm{R}-$ $\left.\mathrm{CO}_{2}^{-}\right) .^{5,6}$ The sulfonate group has been shown to improve the thermal stability of the surfactant at reservoir temperature $\left(60-200{ }^{\circ} \mathrm{C}\right)$, as well as reducing the interfacial tension (IFT), altering the rock wettability, and having lower tendency to adsorb on the surface of sandstone reservoirs. ${ }^{7}$ By contrast, phosphate and sulfated groups have been shown to give low IFTs $^{8}$ and have better performance at lower temperatures, while carboxylated groups have been developed to improve the surfactant stability at high temperatures and high salinity. ${ }^{9}$

Multiple efforts have been made to synthesize the ideal surfactant with the exact physiochemical properties to effectively drive oil out through reservoir pores. Despite many successful designs on a laboratory scale, applying surfactant on a field scale still remains challenging. The main reasons behind these issues lie with chemical interactions within surfactant, oil, and rock charges. Improving the salt tolerance, thermal stability, polymer compatibility, as well as considering the cost and commercial availability of surfactants are essential factors to consider in order for EOR to succeed. Based upon the relative performance of various head groups, we propose that a route to meet these requirements is to synthesize sulfated surfactants with commercially available 
feedstocks that are chemically stable at high temperature in harsh media. Previously prepared sulfated surfactants include, Guerbet alkoxy sulfate (GAS), ${ }^{10}$ alkyl sulfate gemini (ASG), ${ }^{11}$ tristyrylphenol (TSP) alkoxy sulfate, ${ }^{12}$ and alkyl ethoxy sulfate (AES), ${ }^{13}$ all of which have shown potential to alter IFT values and make new surfaces on sandstone reservoirs. ${ }^{14,15}$ These structures have good tolerance in the relatively high saline medium; however, lack of thermal stability leads to their decomposition at higher reservoir temperature $\left(>60{ }^{\circ} \mathrm{C}\right) \cdot{ }^{16}$ Clearly, sulfated surfactants show promise, but the choice of substituent for both stability and cost is important. Based upon our prior work on low surface energy surfactants ${ }^{17}$ and nanomaterials ${ }^{18,19}$ a suitable approach to increasing the stability and solubility of surfactants in harsh environment is through the use of branches hydrocarbon substituents. Advantages of such species include: a high branching factor allows an increase in carbon number without affecting solubility in water due to having a short effective chain length, and branching permits dense surface coverage by promoting efficient packing at interfaces. ${ }^{17} \mathrm{We}$ previously that it is possible to obtain low surface energy single chain hydrocarbon surfactants using commercially available "hedgehog" alcohols. ${ }^{17,20}$ These new low surface energy surfactants (LSESs) can lower the surface tension of pure water as low as $24 \mathrm{mN} . \mathrm{m}^{-}$ ${ }^{1}$, which represents the lowest value for single chain hydrocarbon surfactants. Furthermore, "hedgehog" substituents can be a replacement for highly expensive and hazardous fluorinated and tri-chain surfactants.

Oil displacement by branched surfactant has proven to be a potential remedy to the difficulties in oil sweeping and fluid flow viscous fingering. For example, a branched $\mathrm{C}_{16-17}$ propoxy sulfate, has been shown to be stable in high pressure high temperature (HPHT), resulted in more than $90 \%$ oil recovery. ${ }^{21}$ Despite this result, two major problems still unsolved in surfactant flooding: expense and environmental impact. Herein, we report for the first time, a branched cost-effective 
and environmentally friendly anionic surfactant (I), denoted as $\mathrm{iC}_{18} \mathrm{~S}$ (FO-180) in this work, for use in EOR applications.

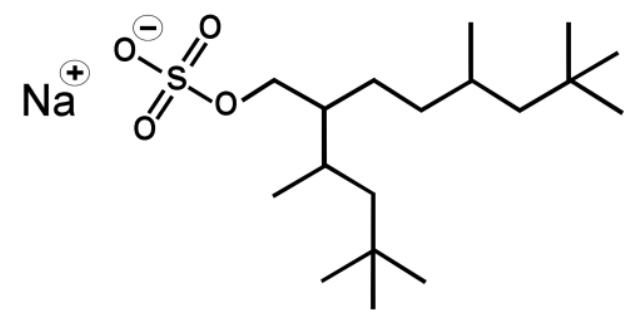

(I)

\section{EXPERIMENTAL SECTION}

Materials. Stock brine solutions ("synthetic sea water") were prepared by dissolving appropriate amounts of potassium chloride $(\mathrm{KCl})$, sodium chloride $(\mathrm{NaCl})$, magnesium chloride hexahydrate $\left(\mathrm{MgCl}_{2} \cdot 6 \mathrm{H}_{2} \mathrm{O}\right)$, and calcium chloride $\left(\mathrm{CaCl}_{2} \cdot 2 \mathrm{H}_{2} \mathrm{O}\right)$, all purchased from SigmaAldrich, in deionized water (resistivity $=18.2 \mathrm{M} \Omega \mathrm{cm}$, Millipore). Isostearyl alcohol $\left({ }^{\mathrm{i}} \mathrm{Pr}\left(\mathrm{CH}_{2}\right){ }_{15} \mathrm{OH},>98 \%\right)$ was provided by Nissan Chemical Industries (Japan). Dichloromethane $\left(\mathrm{CH}_{2} \mathrm{Cl}_{2}, \mathrm{DCM},>99 \%\right)$, chlorosulfonic acid $\left(\mathrm{ClSO}_{3} \mathrm{H},>99 \%\right)$, ethanol $\left(\mathrm{C}_{2} \mathrm{H}_{5} \mathrm{OH}>99 \%\right)$, acetone (99\%), and n-decane $\left(\mathrm{C}_{10} \mathrm{H}_{22}>99 \%\right)$ were purchased from Fisher Scientific and used as supplied.

Synthesis of $\mathrm{iC}_{18} \mathrm{~S}\left(\mathrm{FO}-180\right.$ ) Surfactant. $\mathrm{C}_{18} \mathrm{H}_{37} \mathrm{SO}_{4} \mathrm{Na}$ was synthesized by a modification

of the synthetic methods reported by Alexander et al. ${ }^{17}$ Isostearyl alcohol (10.00 g, $\left.36.96 \mathrm{mmol}\right)$ was dissolved in DCM $(150 \mathrm{~mL})$, and the solution was placed in an ice bath and were kept at $0{ }^{\circ} \mathrm{C}$ for $30 \mathrm{~min}$. Chlorosulfonic acid (1 equiv, $4.30 \mathrm{~g}, 36.9 \mathrm{mmol}$ ) was diluted by $100 \mathrm{~mL}$ DCM and added drop wise to the alcohol solution while the temperature was maintained at $0{ }^{\circ} \mathrm{C}$. The mixture was allowed to warm to ambient temperature and stirred overnight. The solution was neutralized with the mixture of $\mathrm{NaOH}$ in $\mathrm{EtOH}(180 \mathrm{~mL}, 1 \mathrm{M})$ at $\mathrm{pH}$ 8. Subsequently, the solution was evaporated, dissolved in ethanol $(100 \mathrm{~mL})$, and decolorized by charcoal $(1.2 \mathrm{~g})$. The transparent 
waxy gel was left in the vacuum oven overnight at $60^{\circ} \mathrm{C}(30 \mathrm{mbar})$. Finally, the dried sample was dissolved in a small amount of dry acetone and centrifuged for $60 \mathrm{~min}$ at $5000 \mathrm{rpm}$. The final product was obtained by removing the solvent and drying it in the vacuum oven overnight at 70 ${ }^{\circ} \mathrm{C}$. Yield $=11.5 \mathrm{~g}(83.7 \%)$. The surfactant was analyzed using ${ }^{1} \mathrm{H}$ NMR $\left(500 \mathrm{MHz}, \mathrm{CDCl}_{3}, \mathrm{TMS}\right)$ : $\delta 3.75\left(\mathrm{~m}, 2 \mathrm{H},-\mathrm{OCH}_{2}\right), 1.26$ [multiplet $(\mathrm{m}), 11 \mathrm{H}, \mathrm{CH}$ and $\mathrm{CH}_{2}$ ], $0.88\left(\mathrm{~d}, 24 \mathrm{H}, \mathrm{CH}_{3}\right) \mathrm{ppm}$. Elemental analysis (\%): calculated C: 58.0, H: 10.0, S: 8.6; found: C: 57.9, H: 10.6, S: 8.4.

Surfactant Solution Preparation. Twelve synthetic brine and twelve surfactant-brine solutions were prepared for this study (Table S1, see Supporting Information). Solutions were classified into three distinctive classes, by manipulating the ratio of monovalent and divalent cations. The first class of brine solutions, named sea salt water (SSW), according to the amount of full seawater concentration, i.e., "SSW $x \%$ ", where $x=2.5,5,10$, 50, and 100 . The second and third class of solutions: divalent cationic constant (DCC) and monovalent cation constant (MCC), respectively. In DCC solutions, $\mathrm{CaCl}_{2} \cdot 2 \mathrm{H}_{2} \mathrm{O}$ and $\mathrm{MgCl}_{2} \cdot 6 \mathrm{H}_{2} \mathrm{O}$ were constant while $\mathrm{NaCl}$ and $\mathrm{KCl}$ decreased. In contrast, in MCC solutions, $\mathrm{NaCl}$ and $\mathrm{KCl}$ where constant, while $\mathrm{CaCl}_{2} \cdot 2 \mathrm{H}_{2} \mathrm{O}$ and $\mathrm{MgCl}_{2} .6 \mathrm{H}_{2} \mathrm{O}$ were decreased. Each solution was transferred into a $15 \mathrm{~mL}$ borosilicate glass vial, sealed and were mixed gently by a roller mixer over $24 \mathrm{hr}$ at ambient temperature to reach equilibrium. The surfactant brine solutions were prepared by dissolving required quantity of $\mathrm{iC}_{18} \mathrm{~S}(\mathrm{FO}-180)$ in the appropriate brine solutions. Critical micelle concentration (CMC), surface tension at $\mathrm{CMC}$ and the $\mathrm{pH}$ of the surfactant solutions in the presence of salts are given in Table S1 (Supporting Information).

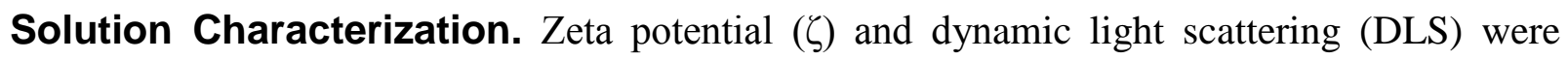
carried out on Zetasizer Nano ZS (Malvern), equipped with 4mW He-Ne solid-state laser $633 \mathrm{~nm}$ and fixed by backscattering angle of $173^{\circ}$. The particle size analysis was averaged of eight runs. 
$\mathrm{pH}$ and electrical conductivity measurements were carried out for each brine and surfactant-brine solution using a conductivity meter (FiveGo Portable F2 pH/mV, METTLER TOLEDO). Before starting each experiment, the conductometer probe was washed with distilled water, ethanol and subsequently calibrated using standard buffer solution at ambient condition.

Surface-interface Analysis. The collection of time-dependent surface tensions, CMCs, IFT, static and dynamic contact angles $(\theta)$ with different volume droplets were performed on a Drop Shape Analyzer (DSA25, Krüss GmbH, Germany) using DI water. The surface tension analysis of $\mathrm{iC}_{18} \mathrm{~S}$ (FO-180) solutions were determined by pendant drop method. For each experiment, the syringe was filled with $1 \mathrm{~mL}$ of the solution, placed in the chamber, and loaded gently. All the measurements were repeated five times, and the average values were reported under ambient conditions. The IFT values between oil-water and oil-surfactant-water with different salinities were measured using the pendant drop method at $20^{\circ} \mathrm{C}$. To evaluate the IFTs, the syringe was filled with $1 \mathrm{~mL}$ of the aqueous solution and was immersed into the oil phase. For each sample, the syringe was calibrated, and the solution was pumped into the oil phase. The droplet shape and interfacial tensions were recorded by an automated camera and were then analyzed using the ADVANCE software (KRUSS GmbH). The static and dynamic IFT values are average of five experiments that were repeated three times. Static (see Supporting Information) and dynamic angle contact of brine and surfactant brine solutions were carried out on three distinct points of a glass substrate to measure the wettability alteration using a sessile drop method. The Young-Laplace equation was used to fit and describe the relationship between the surface parameters.

Adsorption Analysis of Surfactant. Static adsorption isotherms for highly branched surfactant were carried out with crushed glass powder (sieves No. 70) at $20^{\circ} \mathrm{C}$. Our procedure followed the previous method of Ahmadi et al. ${ }^{22}$ Surfactant-brine solutions $(10 \mathrm{~mL})$ were prepared 
and transferred into the vials, then $2 \mathrm{~g}$ of the crushed glass were mixed into the solution, sealed, and were shaken for $5 \mathrm{~min}$. Then each vial was centrifuged at $3000 \mathrm{rpm}$ for $30 \mathrm{~min}$ to reach equilibrium condition. To measure the adsorbed amount of the $\mathrm{iC}_{18} \mathrm{~S}(\mathrm{FO}-180)$ surfactant on the crushed glass, the difference in weight between the aqueous phase surfactant concentration before and after adsorption were measured. In this case, adsorption isotherms (Q) have been calculated based on the following equation (Eq. 1), where $Q$ is the amount of surfactant adsorption (mg. $\mathrm{g}^{-1}$ ) on the solid substrate, $m_{\text {Total }}$ and $m_{\text {Glass }}$ are the total mass of solution $(\mathrm{g})$ and crushed glass $(\mathrm{g})$ respectively, $C^{0}$ and $C$ are initial and final surfactant concentration $\left(\mathrm{mg} . \mathrm{L}^{-1}\right)$ before and after equilibrating adsorption on the crushed glass, respectively. $C^{0}$ and $C$ concentration measurements were carried out using electrical conductometer measurements to record the exact amount of surfactant concentrations in different system.

$$
Q=\frac{m_{\text {Total }}\left(C^{o}-C\right)}{m_{\text {Glass }}} * 10^{-3}
$$

Rheological Measurements. The rheological properties of the $\mathrm{iC}_{18} \mathrm{~S}(\mathrm{FO}-180)$ surfactant solutions were implemented using the rotational DV3T Rheometer (AMETEK Brookfield). Each solution was placed in the cylinder, and shear rate and viscosity were measured by increasing the spindle torque. The viscosity, and shear stress-shear rate curves were analyzed using the Powerlaw (Ostwald) model, Eq. 2, where $\tau, \kappa, \ddot{Y}$ and $n$ are shear stress, flow consistency index $\left(P . s^{\mathrm{n}}\right)$, shear rate $\left(\mathrm{s}^{-1}\right)$, and flow behavior index, respectively. When $\mathrm{n}>1$ fluid has shear thickening behaviors, $\mathrm{n}=1$ fluid flow is Newtonian, while $(\mathrm{n}<1)$ predicts non-Newtonian (pseudo-plastic) behavior, which means that the effective viscosity will decrease by increasing shear rates. Physical chemistry of the fluid such as their effective viscosity has the significant effect on the fluid behavior, which can be described by Power-low model. Furthermore, viscosity $(\mu)$ can be derived 
from the defined $\kappa$ and $\ddot{Y}$ parameters and were fitted by the following power-law equation (Eq. $3) .^{23}$

$$
\begin{gathered}
\tau=\kappa * \ddot{\Upsilon}^{n} \\
\mu=\kappa * \ddot{\Upsilon}^{n-1}
\end{gathered}
$$

Micromodel Fabrication. In order to measure the oil displacements after each flooding, a quasi-two-dimensional glass microfluidic pattern with heterogeneous form has been employed. This system helps to observe in-depth interactions between fluid-fluid and solid-fluid along the flooding in porous media. The heterogeneous pattern (Figure 1) was simulated from a cross-section of sandstone rock and etched by a $\mathrm{CO}_{2}$ laser on the transparent glass substrate: $\mathrm{SiO}_{2}(74.5 \%), \mathrm{Na}_{2} \mathrm{O}$ (14\%), $\mathrm{CaO}(6.3 \%), \mathrm{K}_{2} \mathrm{O}(1 \%)$, and $\mathrm{Al}_{2} \mathrm{O}_{3}(0.6 \%)$. The size of micropattern glass was $70 \times 140$ $\mathrm{mm}^{2}$. The etched pattern was cleaned with soap and acetone, and then was dried in an oven for 30 min. Another entirely smooth glass covered over it and were annealed in the furnace for $8 \mathrm{hr}$ at $720^{\circ} \mathrm{C} .{ }^{3}$ Darcy's law equation was used to calculate the effective porosity, permeability and etched thickness $(\varphi=22 \%, \kappa=6.3 \mathrm{mD}$, and $\mathrm{L}=35 \mu \mathrm{m})$ before measuring the oil displacement. Figure 1 shows the schematic diagram of microfluidic apparatus. The oil displacements pictures were taken by Nikon camera and analyzed using Image processing software (ImageJ).

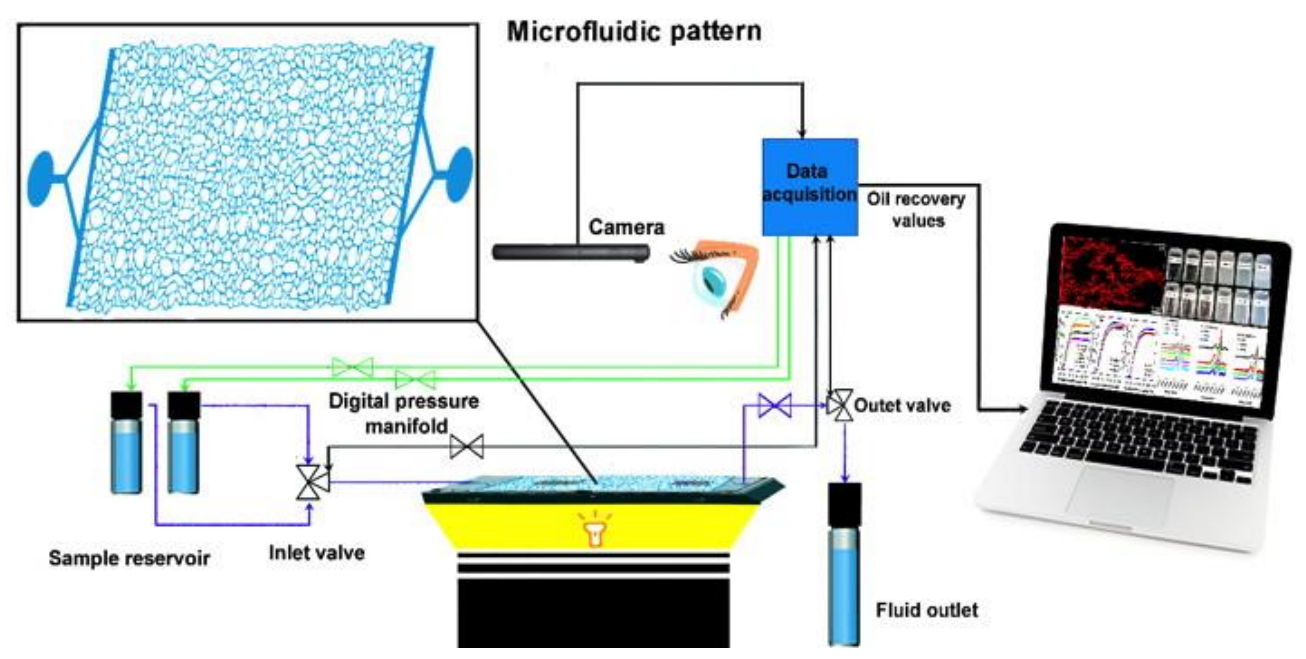


Figure 1. Schematic representation of the microfluidic pattern and apparatus for oil recovery experiment.

Surfactant-brine and Brine Flooding. Solution flooding at $25{ }^{\circ} \mathrm{C}$ was performed on heterogeneous sandstone pattern (Figure 1). An ultralow flow rate Quizix pump and a high sensitive transducer were used to precisely measure the differential pressures and injection flow rates, respectively. In each flooding, the pattern was saturated with six-pore volume (PV) of brine water (initial water saturation; $S_{w i}=100 \%$ ), then $n$-decane (oil phase) gently injected until the pressure no longer changed (saturated oil-wet condition $\mathrm{S}_{\mathrm{oi}}=100 \%$ ) and the pattern was aged for $48 \mathrm{hr}$ until the pattern became oil-wet. Finally, the flooding was performed at the constant injection flow rate $\left(0.005 \mathrm{~cm}^{3} \cdot \mathrm{min}^{-1}\right)$ to measure the amount of oil recovery for two defined systems: (1) brine solutions and (2) surfactant-brine solutions. The residual oil saturation in both scenarios was evaluated using ImageJ software.

Small-angle Neutron Scattering. The SANS experiments were carried out at the ISIS facility, Rutherford Appleton Laboratory, UK on the LOQ instrument. LOQ is a fixed-sample detector instrument that uses a white neutron beam with wavelengths between 2.2 and $10.0 \AA$ to provide a Q-range of $0.006-1.0 \AA^{-1}$. All samples were measured in $2 \mathrm{~mm}$ path-length rectangular quartz cells, and raw SANS data were normalized by subtracting the scattering of the empty cell and a solvent background. Each solution was prepared using $\mathrm{D}_{2} \mathrm{O}$ (uniform scattering length density (SLD); $\rho=6.33 \times 10^{-6} \AA^{-2}$ ) and transferred into $2 \mathrm{~mm}$ rectangular quartz cell cuvettes, sealed and were placed into the SANS rack where measurements were carried out at 25 and $80{ }^{\circ} \mathrm{C}$. The Mantid ${ }^{24}$ programs was used for data reduction and SANS data were fitted using the fitting program SansView (http://www.sasview.org/), which uses an iterative, least-squares fitting process. The details of the fitting models used here are given in the supporting materials. The 
scattering length densities for $\mathrm{iC}_{18} \mathrm{~S}(\mathrm{FO}-180)$ is calculated to be around $1.80 \times 10^{-7} \AA^{-1}$. The data were fitted to a lamellar structure for the surfactants in pure water and to a cylindrical and spherical model in the presence of brine. The details of the models are given in the supporting information.

\section{RESULTS AND DISCUSSION}

Surfactant Characterization. The main parameters of the $\mathrm{iC}_{18} \mathrm{~S}(\mathrm{FO}-180)$ surfactant (such as

branching factor and $\mathrm{CMC}$ ) in pure water have been reported previously. ${ }^{17}$ Herein we focus on the characterization of the surfactant in various brine concentrations. As is shown in Figure 2a, the presence of counter ion affects the surface tension and $\mathrm{CMC}$ of $\mathrm{iC}_{18} \mathrm{~S}(\mathrm{FO}-180)$ solutions. The CMC values were obtained using the intersection point lines precisely above and below the breakpoint. The CMC values of surfactant-brine solutions decrease from $2.7 \mathrm{mM}$ (in pure water) to $1.4 \mathrm{mM}$ as the salt concentrations increase (CMC values for each salt concentration are given in Table S1, see Supporting Information). In general it was found that the solubility of $\mathrm{iC}_{18} \mathrm{~S}(\mathrm{FO}-180)$ in water is higher in lower brine concentration and follow: PW > SSW-2.5\%>SSW-5\% $>\mathrm{SSW}-10 \%>$ SSW-50\% $>$ SSW-100\%. As the percentage of brine increases to above $10 \%$, a salting out effect was observed and the surfactants precipitated out (shown in Figure S1, Supporting Information). The pure water surfactant solution is cloudy; however, the solutions become clearer as $\mathrm{iC}_{18} \mathrm{~S}(\mathrm{FO}-$ 180) solubility decreases due to the precipitation of the surfactant. The $\gamma_{c m c}$ values increase with the brine concentration: the surfactant in pure water has the lowest $\gamma_{\mathrm{cmc}}$ of $25.5 \mathrm{mN} \cdot \mathrm{m}^{-1} .{ }^{17}$ Addition of electrolyte to ionic surfactant solutions leads to greater solubilization of the inner core (hydrocarbon parts) of micelles resulting in extent decrease in polarity between the hydrophobic tail and head in surfactant micelles. ${ }^{25}$ Thus, it can be expected that interaction between counter ions and surfactants, decrease the electrostatic repulsion between their ionic head groups and 
consequently causes the decrease in their CMC value, promote aggregation number, and increase the volume of micelles. ${ }^{26}$
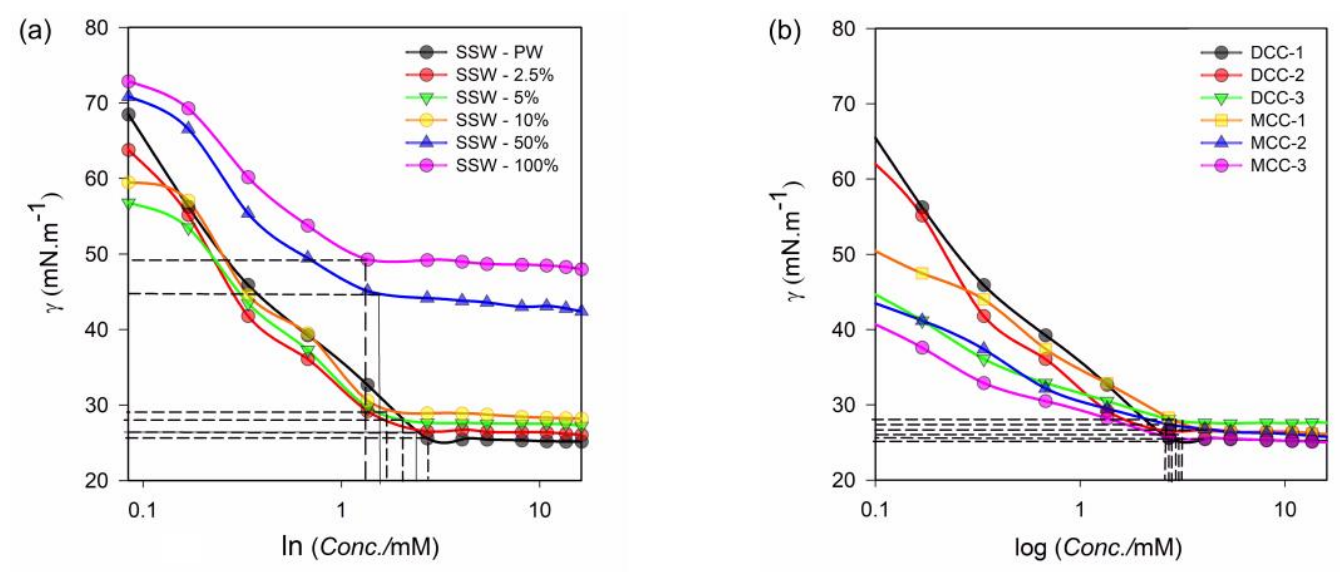

Figure 2. Surface tension behavior of the single chain surfactant $\mathrm{iC}_{18} \mathrm{~S}(\mathrm{FO}-180)$ (I) in (a) water and (b) brine solutions (see Table S1, Supporting Information).

Figure $2 \mathrm{~b}$ shows that the surface tensions in the MCC and DCC series change when the concentration of monovalent and divalent cations are varied, and are as follow: DCC-1 > DCC-2 $>$ DCC-3 and MCC-1 > MCC-2 > MCC-3. In EOR applications, lower surface tension is governed by surfactant at the fluid-rock interface, causing effective oil sweeping, while in pure brine solution removing oil from the rock pores is difficult due to the high surface tension of the solution, as can be seen in Figure 3. 


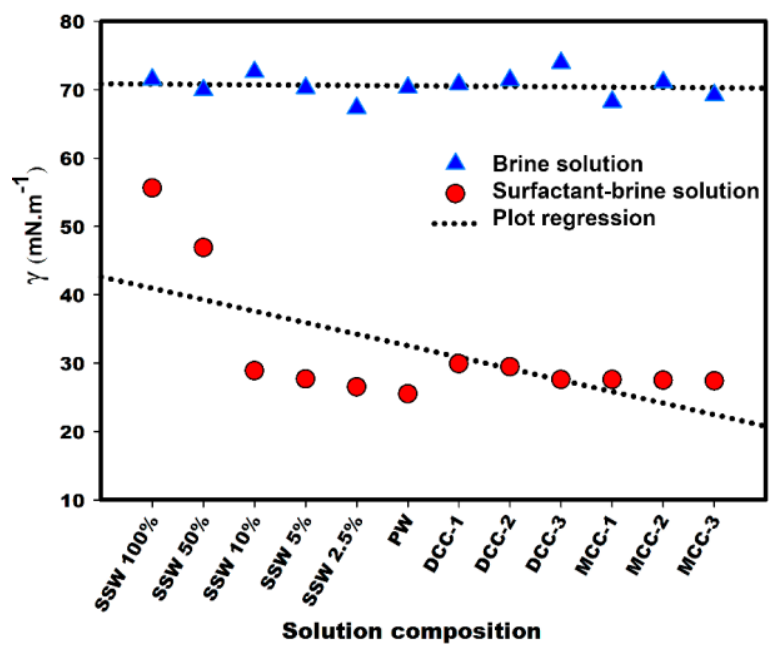

Figure 3. Comparison of surface tension values (at $\mathrm{CMC}$ ) of pure brine solutions and $\mathrm{iC}_{18} \mathrm{~S}$ (FO180)-brine solutions.

Effect of Brine and Surfactant-Brine on IFT of Oil. The pendant drop method was performed in order to find out the effect of brine and the surfactant-brine solutions on the IFT values. Figure 4 shows a schematic representation of the IFT mechanism of brine and surfactantbrine solution in $\mathrm{n}$-decane. It shows that using a surfactant in oil-brine system lead to a significant decrease in IFT and volume droplet size. The strong chemical bonding between water molecules in brine solutions forms large spherical water droplets inside the oil phase (i.e., Figure 4a), while the surfactant solution forms small oval shape droplets (Figure 4b). The higher the brine concentration the higher the droplet size observed (Figure S3, Supporting Information). 


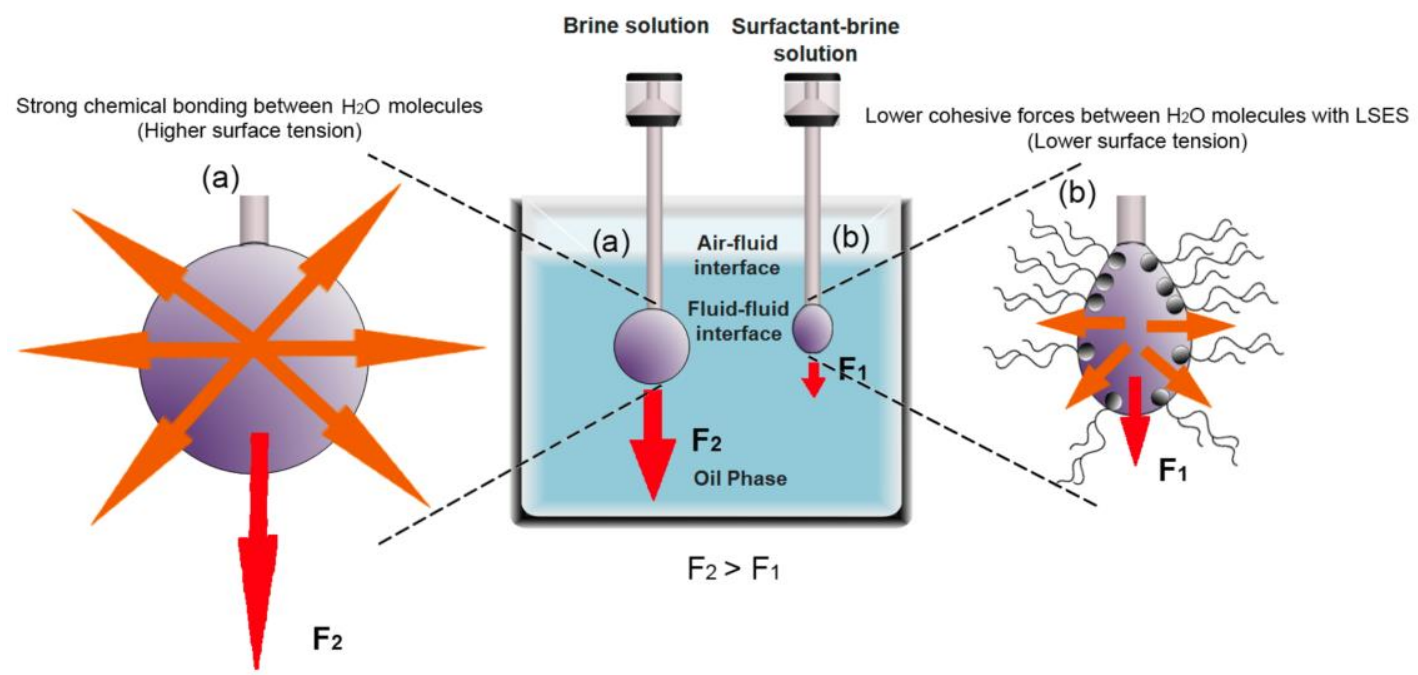

Figure 4. IFT mechanism of (a) surfactant-brine and (b) brine in $n$-decane.

Dynamic IFT measurements were conducted on brine droplets over $1200 \mathrm{sec}$ in n-decane and are shown in Figure 5. As can be seen in Figure 5a, raising the brine concentration from $2.5 \%$ to $100 \%$ in SSW series increases the IFT by around $12 \mathrm{mN} \cdot \mathrm{m}^{-1}$. For an oil-brine solution, it is expected that IFT would increase with higher counter ions. This could be a result of hydrogen bonds caused by counter ions in the presence of oily polar components, ${ }^{27}$ nevertheless, the mechanism behind this change is still unknown. Figure $5 \mathrm{~b}$ and compares the IFT values by reducing divalent and monovalent cations in n-decane, respectively. Lowering the divalent cations concentration for MCC and monovalent for DCC solutions also caused reducing the IFT from 60 to $57 \mathrm{mN} \cdot \mathrm{m}^{-1}$. 

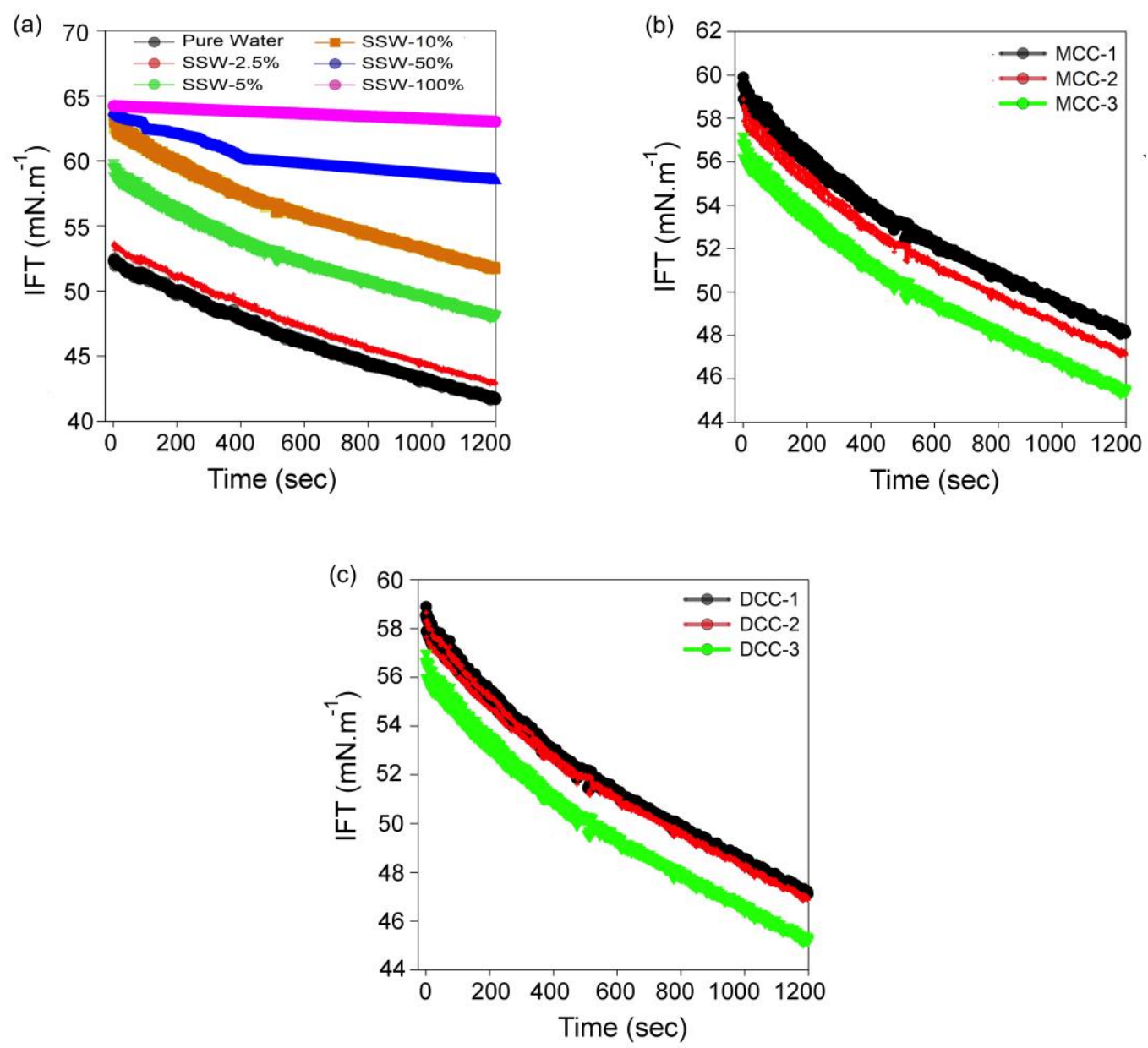

Figure 5. Dynamic IFT of brine droplets in $n$-decane at 1200s. (a) SSW series, increase of the brine concentration from SSW-2.5\% to SSW-100\% (b) MCC at varying divalent cations and (c) DCC at varying monovalent cations.

IFT measurements of surfactant-brine droplets in oil over $1200 \mathrm{~s} \mathrm{sec}$ are illustrated in Figure 6 (the static IFT data are shown in the supporting information Table S2). Comparing the data in Figure 6 with data in Figure 5 shows that the addition of surfactant to the brine solutions results in significant reduction of IFT by nearly 50-60 mN.m ${ }^{-1}$. Among the SSW surfactant-brine solutions (Figure 6a), SSW (2.5\%, 5\%, and 10\%) showed lower IFT compared to SSW 50\% and 100\%. In anionic surfactant, decreasing IFT values is due to the decreases of electrical repulsion force between ionic head groups and were found to decrease the size of micelle. ${ }^{28}$ Over $1200 \mathrm{sec}$, mean 
IFT values were measured as $\sim 0.5 \mathrm{mN} . \mathrm{m}^{-1}$ for pure water and $\sim 3.3 \mathrm{mN} . \mathrm{m}^{-1}$ for $\mathrm{SSW}-100 \%$, respectively. Furthermore, IFT values on DCC and MCC systems were studied separately in surfactant-brine solutions. Based on the results in Figure 6b, reduction of divalent cations in MCC series $\left(\mathrm{Ca}^{2+}\right.$ and $\left.\mathrm{Mg}^{2+}\right)$ has higher impact in decreasing IFT compared to reduction of monovalent cations $\left(\mathrm{Na}^{+}\right.$and $\left.\mathrm{K}^{+}\right)$in DCC solutions (Figure 6c). Hence, the present experiment show that the high IFT values in surfactant-brine system caused by higher adsorption of divalent cations $\left(\mathrm{Ca}^{2+}\right.$ and $\mathrm{Mg}^{2+}$ ) compared to the monovalent cations at solution interface. Reducing IFT values in the reservoir should result in deposition of surfactant on the surface and create a new surface on substrate as well as mobilizing residual oil through the pores, as explained in detail in different literature. ${ }^{3,13,29}$ It is observed that the branched LSES surfactant, $\mathrm{iC}_{18} \mathrm{~S}(\mathrm{FO}-180)$, can limit the surface energies between two immiscible fluids (reducing in IFT values) and could provide new chemical interactions, which lead to faster changes in wettability.
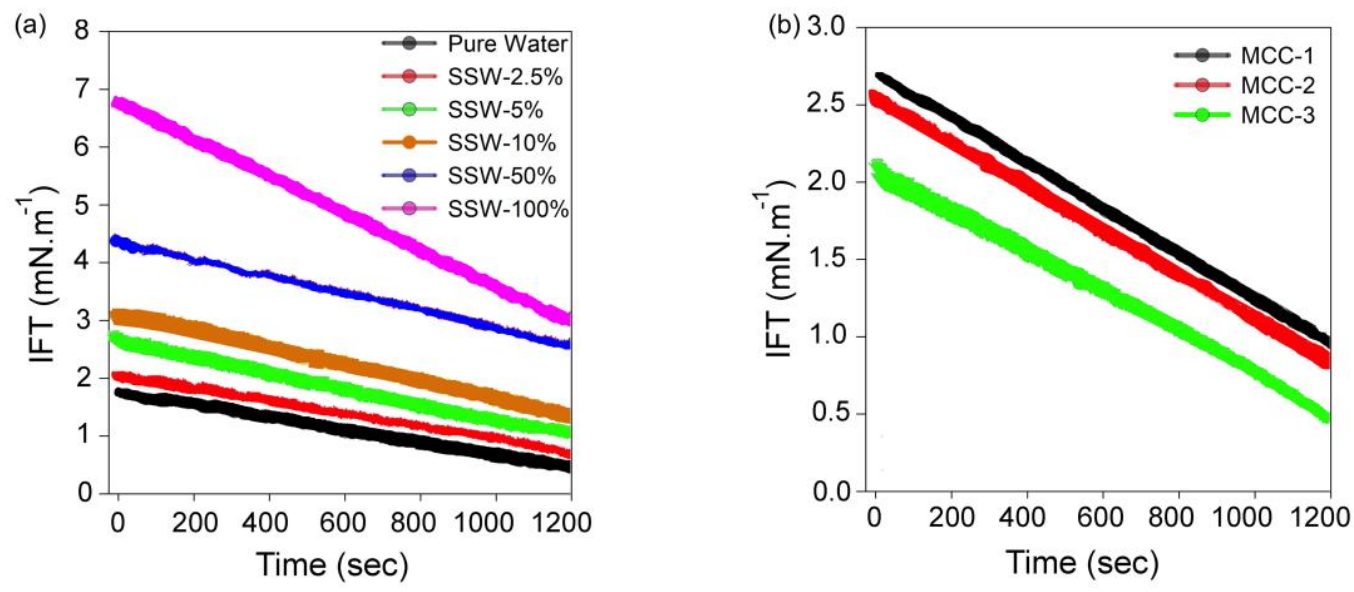


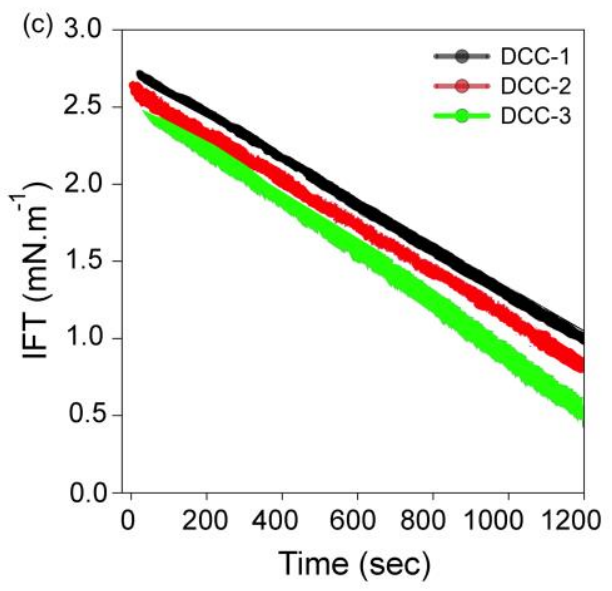

Figure 6. Dynamic IFT of surfactant-brine droplets in $n$-decane over the 1200s. (a) SSW series; from SSW-2.5\% to SSW-100\% (b) MCC at varying divalent cations and (c) DCC at varying monovalent cations.
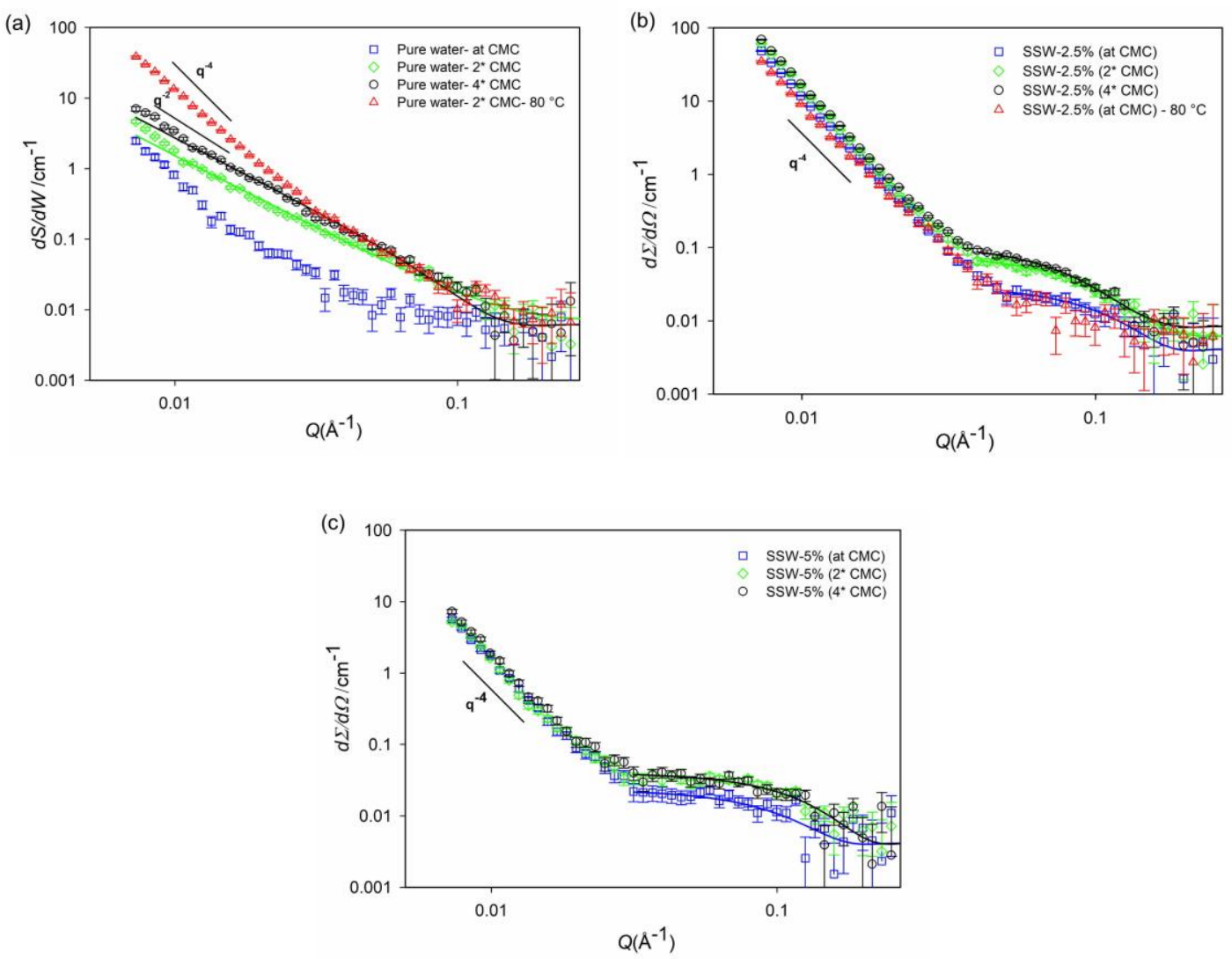

Figure 7. SANS patterns of $\mathrm{iC}_{18} \mathrm{~S}(\mathrm{FO}-180)$ (at, 2 and $4 \times \mathrm{CMC}$ ) in pure water (a), in the presence of SSW $2.5 \%$ (b) and SSW $5 \%$ (c) at $25^{\circ} \mathrm{C}$ and $80{ }^{\circ} \mathrm{C}$. 
Aggregation Structures. SANS data were collected for the single chain surfactant $\mathrm{iC}_{18} \mathrm{~S}$ (FO180) (at and above CMC) as a function of salt concentration. The measurements were carried out at both $25{ }^{\circ} \mathrm{C}$ and $80{ }^{\circ} \mathrm{C}$ to examine the aggregation behavior of $\mathrm{iC}_{18} \mathrm{~S}(\mathrm{FO}-180)$ in ambient and reservoir conditions. The scattering patterns of the surfactant in pure water and at various salt concentrations and temperature are shown in Figure 7. Details on the fitting models and their equations are given in the Supporting Information.

Data for samples with pure surfactant at concentrations of $2 \times$ and $4 \times \mathrm{CMC}$, (Figure $7 \mathrm{a}$ ), were fit to the unilamellar structure with a bilayer thicknesses (D) of $22 \pm 5$ and $33 \pm 1 \AA$, respectively which is in line with the results shown previously. ${ }^{17}$ The data at CMC, within the resolution of the intensity scale and $Q$ range studied here, demonstrate the absence of any aggregation structure at high Q values; however, the scattering at low $Q$ values is likely to be residual lamellar fragments. The pure surfactant with concentration of $2 \times \mathrm{CMC}$ at $80^{\circ} \mathrm{C}$ was also examined by SANS and the data shows that scattering pattern changed at the lower $\mathrm{Q}$ region from $\mathrm{Q}^{-2}$ which is expected for lamellar sheets to $\mathrm{Q}^{-4}$ which is related to the scattering from sharp interfaces of particles. However, there is a diffraction peak at $\mathrm{Q}=0.11 \AA^{-1}$, which could be due to the lamellar bilayers.

Figure $7 \mathrm{~b}$ shows the scattering pattern of $\mathrm{iC}_{18} \mathrm{~S}(\mathrm{FO}-180)$ at 3 different concentrations in the presence of $2.5 \%$ brine solutions at $25{ }^{\circ} \mathrm{C}$ and $80{ }^{\circ} \mathrm{C}$. As can be seen from the scattering patterns, upon addition of electrolyte SSW $2.5 \%$ to surfactant solutions at CMC, an aggregation pattern is observed which indicate that the lowest salt concentration (studied here) promote the aggregation of the surfactant. We propose that this is because the ions reduce the electrostatic repulsion among the surfactant head groups and help the growths of the aggregates by lowering the CMC (see above). However, the pattern could not be fit to a single model and it appears to be biphasic, consisting of coexisting of dilute sphere micellar phase at high $\mathrm{Q}$ values $\left(0.05<\mathrm{Q}<0.3 \AA^{-1}\right)$ with 
radii of $22 \pm 2 \AA$ and $\mathrm{Q}^{-4}$ Porod scattering of large interfaces of particles at lower Q region. As the concentration of surfactant increases the scattering of the micellar phase become more dominant and the data at lower Q values were fitted to a cylindrical model for both $2 \times$ and $4 \times \mathrm{CMC}$ samples with a cylinder radius of $19 \pm 2 \AA$ and a cylinder length of $55 \pm 5 \AA$. This biphasic behavior was observed previously for double chain surfactants with various counter ions as well as surfactants in the presence of brines. ${ }^{30-32}$

Figure $7 \mathrm{c}$ shows the scattering pattern of $\mathrm{iC}_{18} \mathrm{~S}(\mathrm{FO}-180)$ in the presence of $5 \%$ brine solutions. As can be seen from the data, the scattering intensity decreases significantly as the concentration of salt increases. The scattering pattern at high Q values was fitted to a sphere model with radius of $22 \pm 3 \AA$ for surfactant solution at CMC and radius of $19 \pm 2 \AA$ for concentrations above the CMC. No scattering pattern was observed for $\mathrm{iC}_{18} \mathrm{~S}(\mathrm{FO}-180)$ in SSW $5 \%$ at $80{ }^{\circ} \mathrm{C}$. Increasing the concentration of brine to $10 \%$ and beyond reduces the surfactant stability and the precipitation was observed (salting out effect). No clear scattering pattern was observed for these solutions as is shown in Figure S5 of the supporting information

Rheology measurements. The rheological behavior is an important parameter that usually provides a well-defined guideline for a successful EOR flooding. Having suitable microscopic oil displacer with an appropriate viscosity is needed to make a homogeneous front of surfactant to suppress the fluid viscous fingering in pore-scale. ${ }^{3,33}$ The rheology of solutions in various brine concentrations are shown in Figure 8. 

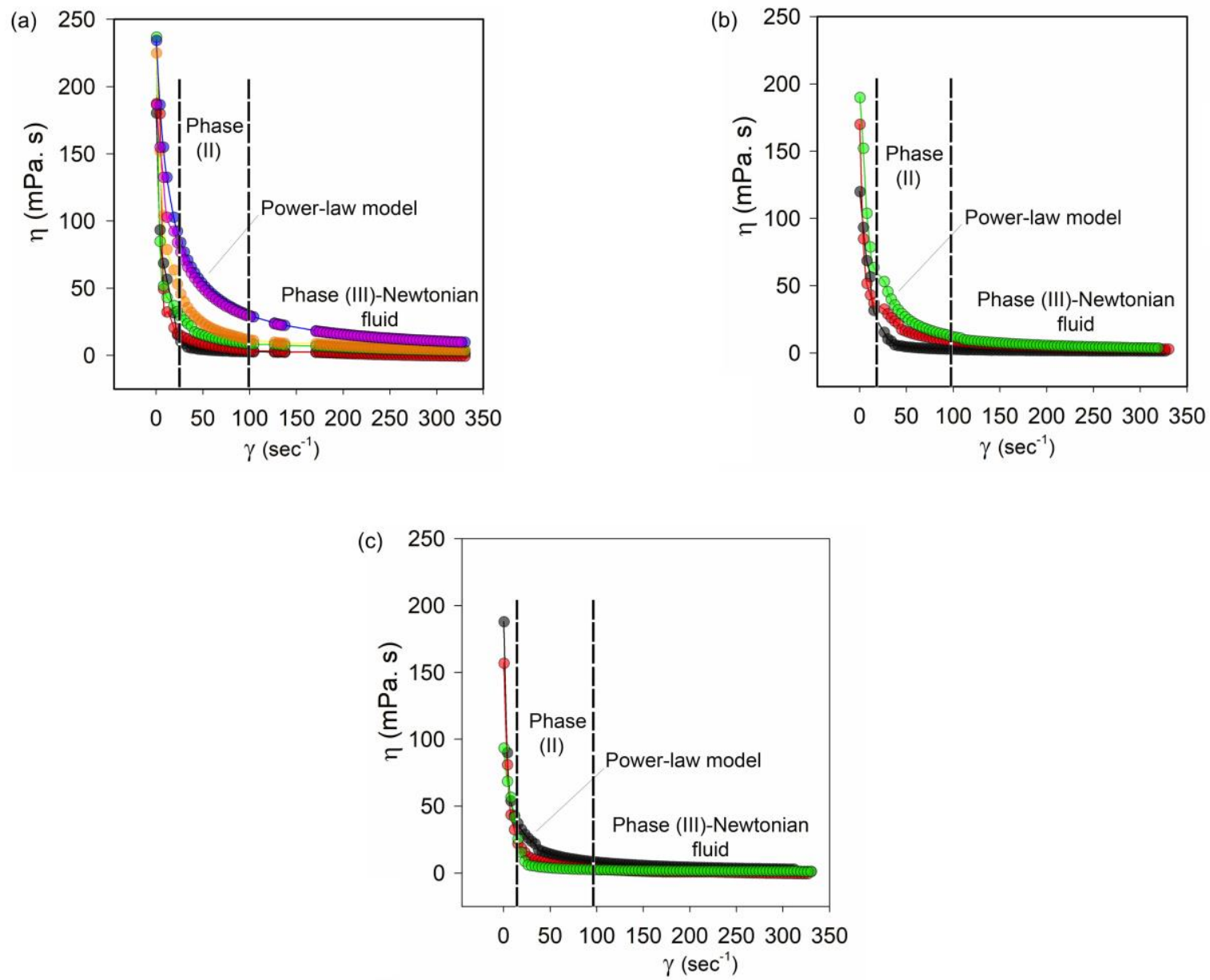

Figure 8. Time-dependence viscosity-shear rate of surfactant-brine solutions over $350 \mathrm{~s}$ : (a) SSW series, (b) MCC, and (c) DCC series. The viscosity and shear rate standard errors are $\pm 20 \mathrm{mPa} . \mathrm{s}$ and $\pm 2 \mathrm{~s}^{-1}$, respectively.

Figure 8 a shows that the viscosity $(\mu)$ values increase for lower brine concentration $(\mathrm{SSW}-2.5 \%$ to SSW-10\%) and then decrease by increasing the brine concentration (SSW-50\% to SSW-100\%). The main reason behind the increase in viscosity of surfactant solution (SSW-2.5\% to SSW-10\%) is most likely due to the rearrangement of surfactant molecular structure (micelle and their aggregation number) as was observed for the SANS measurements (see above). These results are in line with previously reported data for $\mathrm{CTAB} /$ brine solutions. ${ }^{34}$ The rheological properties of $\mathrm{MCC}$ and DCC series are shown in Figure $8 \mathrm{~b}$ and c. We found that a decrease in divalent cations $\left(\mathrm{Ca}^{2+}\right.$, 
$\mathrm{Mg}^{2+}$ ) in surfactant-MCC solutions cause increasing fluid viscosity (MCC-3 $>$ MCC-2 $>$ MCC-1). However, decreasing monovalent cations $\left(\mathrm{Na}^{+}\right.$and $\left.\mathrm{K}^{+}\right)$in DCC solutions cause less increase in their viscosities (DCC-1 > DCC-2 > DCC-3).

In phase I (Figure 8), the magnitude of apparent viscosity has decreased for all the solutions at lower shear rates $\left(0-30 \mathrm{~s}^{-1}\right)$. The same trend of viscosities was also observed in brine solutions (Figure S4, Supporting Information). Phase II (35-100 $\left.\mathrm{s}^{-1}\right)$ shows that when the shear rate increases, the $\mu$ values decrease, this means the fluids have shear-thinning (pseudo-plastic) behavior. ${ }^{3}$ We note here that pseudo-plastic behavior must be taken into account during successful surfactant EOR scenarios to release the entrapped oil into the pores by the capillary mechanism. ${ }^{35}$ In the final step (phase III), extreme shear rate causes a faster decrease in $\mu$ and reach the Newtonian behave $\left(100-330 \mathrm{~s}^{-1}\right)$.

Effect of Counter lons on Zeta Potential. It is widely agreed that the effect of counter ions on surfactant structures leads to significant changes in oil mobilization through the rock pores. ${ }^{36}$ Interactions between counter ions and hydrophilic head groups have an important role on making a successful oil recovery operation. Thus, zeta potential $(\zeta)$ measurements have been carried out to determine the charge distribution of surfactant in brine solutions (Table 1) and the impact of monovalent and divalent cations on the $\zeta$ values of surfactant solutions.

As is shown in Table 1, increasing salt species in the SSW series from pure water to SSW-10\%, results in a change in the $\zeta$ values from -62.5 to $-25 \mathrm{mV}$. The data shows the optimum surfactant stability is in lower salt concentrations (below SSW-10\%). It should be noted that no reliable data was obtained for the surfactant brine solutions at 50 and $100 \%$ as the solutions were not fully stable, due to the presence of extreme electrostatic forces associated with these solutions. ${ }^{36}$ Also, it has been previously reported for EOR using surfactants that solutions in their most stable form 
have $\zeta$ values above $+30 \mathrm{mV}$ and below $-30 \mathrm{mV}$, while $\zeta$ values for unstable solutions are between $-30 \mathrm{mV}$ and $+30 \mathrm{mV} \cdot{ }^{37}$ It was also found that decreasing amount of $\mathrm{Ca}^{2+}$ and $\mathrm{Mg}^{2+}$ concentrations for MCC solutions increase the fluid stability and therefore resulted in lower $\zeta$ values (from around -36 to $-59 \mathrm{mV}$ ). This behavior can be explained by the fact that the micelles in the absence of divalent cations can overcome more electrostatic forces between the hydrophobic tail and head group. ${ }^{25}$ On the contrary, upon decreasing $\mathrm{Na}^{+}$and $\mathrm{K}^{+}$the physical appearance of the DCC brine solutions (their turbidity) changed, leading to increase in the $\zeta$ values. Such inconsistent behavior in DCC solution, compared to SSW and MCC solutions, raises the assumption that decreasing monovalent cations $\left(\mathrm{Na}^{+}\right.$and $\left.\mathrm{K}^{+}\right)$leads to decreasing electrostatic repulsion between the ionic head groups.

Table 1. Average zeta potential (५), particle size (nm) values, and $\mathrm{iC}_{18} \mathrm{~S}(\mathrm{FO}-180)$ adsorption on the substrate at different brine solutions.

\begin{tabular}{lllll} 
Sample & $\begin{array}{l}\text { Zeta potential } \\
(\mathbf{m V})\end{array}$ & $\begin{array}{l}\text { Electrophoretic } \\
\text { mobility }(\boldsymbol{\mu m . c m} / \mathbf{V . s})\end{array}$ & $\begin{array}{l}\text { Mean size }(\mathbf{d}) \\
(\mathbf{n m})\end{array}$ & $\mathbf{Q}^{*}\left(\mathbf{m g} \cdot \mathbf{g}^{-1}\right)$ \\
\hline PW-LSES & $-62.5 \pm 4$ & $-4.8250 \pm 0.6$ & $78.8 \pm 25$ & $5.1 \pm 0.1$ \\
SSW-2.5\% & $-39.6 \pm 4$ & $-3.1250 \pm 0.5$ & $91.3 \pm 15$ & $5.7 \pm 0.1$ \\
SSW-5\% & $-30.6 \pm 5$ & $-2.5400 \pm 0.8$ & $106 \pm 12$ & $6.9 \pm 0.15$ \\
SSW-10\% & $-22.4 \pm 5$ & $-1.5380 \pm 0.2$ & $142 \pm 12$ & $7.3 \pm 0.2$ \\
SSW-50\% & $-1 \times 10^{-3}$ & $-1.00 \times 10^{-3}$ & $640 \pm 30$ & $9.1 \pm 0.3$ \\
SSW-100\% & $-2.3 \times 10^{-3}$ & $-400 \times 10^{-6}$ & $855 \pm 45$ & $10.3 \pm 0.4$ \\
DCC-1 & $-40.4 \pm 2$ & $-3.1650 \pm 0.5$ & $164 \pm 15$ & $7.6 \pm 0.05$ \\
DCC-2 & $-34.6 \pm 3$ & $-2.7500 \pm 0.2$ & $190 \pm 13$ & $7.7 \pm 0.05$ \\
DCC-3 & $-24.2 \pm 3$ & $-1.8570 \pm 0.1$ & $220 \pm 12$ & $7.8 \pm 0.05$ \\
\hline
\end{tabular}


Surfactant Adsorption on Solid Substrate. Study of surfactants adsorption is often problematic as there are many different parameters that can affect the adsorption of surfactants on the solid substrate including surfactant structure (size, and morphology), dissolved charges in fluids and rock surface charges. ${ }^{38-40}$ The binding affinities of surfactants cause significant changes in the IFT, contact angle, and rock wettability alteration. ${ }^{29}$ In reservoirs, lower surfactant adsorption and minimum loss onto the rock substrate results in higher oil recovery. $\mathrm{The}_{\mathrm{iC}} \mathrm{C}_{18} \mathrm{~S}$ (FO180) adsorption values, Q (mg. $\left.\mathrm{g}^{-1}\right)$, were obtained for SSW series using Eq. 1 and are shown in Table 1. The surfactant adsorption trends on the substrate generally corresponded with the increasing of salt contents and it is as follow: pure water $<\mathrm{SSW}-2.5 \%<\mathrm{SSW}-5 \%<\mathrm{SSW}-10 \%<$ SSW-50\% < SSW-100\%. The intermolecular forces (electrostatic, van de Waals, and chemical bonding) in surfactant/brine/substrate cause higher adsorption in harsh condition. ${ }^{1,20,29,41}$ To our knowledge, further increasing electrostatic repulsion forces has caused higher surfactant adsorption on the substrate. ${ }^{30}$ It should be noted that a distinct increase in hydrophobicity of surfactant caused a salting-out effect ${ }^{42}$ in aqueous phase while no surfactant retention was observed in maximum brine concentration (SSW-50\% and SSW-100\%). Therefore, more brine diffusion in micelles leads to the migration of unimers from the surfactant micelles to the interface.

The difference in the surfactant adsorption in MCC and DCC series also are outlined in Table1. It is found that the surfactant in MCC solutions has more tendencies to be adsorbed on the substrate than DCC solutions. Upon decreasing $\mathrm{Ca}^{2+}$ and $\mathrm{Mg}^{2+}$ in $\mathrm{MCC}$ solutions, $\mathrm{Q}$ showed a decreased from 8.1 to $7.2 \mathrm{mg} \cdot \mathrm{g}^{-1}$. It seems, divalent cations $\left(\mathrm{Ca}^{2+}\right.$ and $\left.\mathrm{Mg}^{2+}\right)$ in the surfactant solution interact more than monovalent cations $\left(\mathrm{Na}^{+}\right.$and $\left.\mathrm{K}^{+}\right)$with the negatively charges and caused more adsorption on the substrate. This is presumably due to the strong chemical interactions between positive charges of $\mathrm{Ca}^{2+} / \mathrm{Mg}^{2+}$ onto the negatively charges of the rock substrate. ${ }^{25}$ The lower 
adsorption affinities for these solutions follow MCC-1 > MCC-2 > MCC-3. Reduction of monovalent cations $\left(\mathrm{Na}^{+}\right.$and $\left.\mathrm{K}^{+}\right)$demonstrates slightly increased adsorption from DCC-1 to DCC3. Clearly it shows the adsorption affinities in MCC are more than DCC solutions.

\section{Impact of Surfactant-brine and Brine Solutions on Droplet Contact Angles. The} contact angle of the solutions on the glass substrate (used for the microchannel experiments, see Experimental) was measured after a rapid deposition of droplets on the glass substrate. Figure 9 shows the droplet pictures for pure water and brine solutions and the resulting dynamic contact angle data (the static and hysteresis contact angles are given in the supporting information Table S3). In SSW series, increasing brine concentrations led to raising the contact angle on the glass substrates from $51^{\circ}$ to $60^{\circ}$ (Figure $9 \mathrm{a}$ ) and it remained unchanged up to $1000 \mathrm{sec}$. Furthermore, after $1000 \mathrm{sec}, \theta$ values of pure water decreased to $32^{\circ}$ from $51^{\circ}$, while in SSW- $100 \%$ it reached to $45^{\circ}$ from $60^{\circ}$. These results confirmed that the glass substrate is in the range of intermediate wet. ${ }^{28}$ This trend was also observed for the MCC and DCC series.

(a)

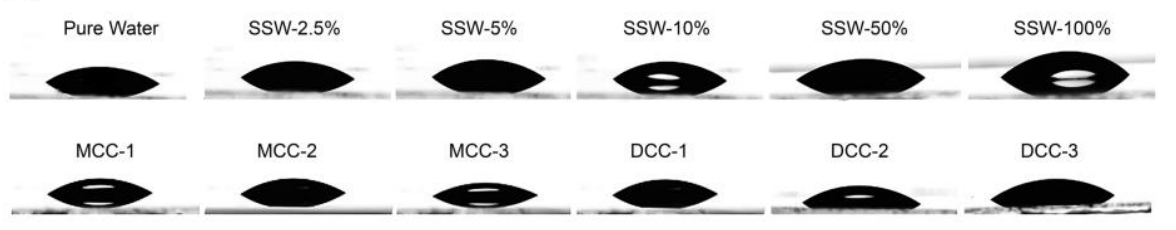



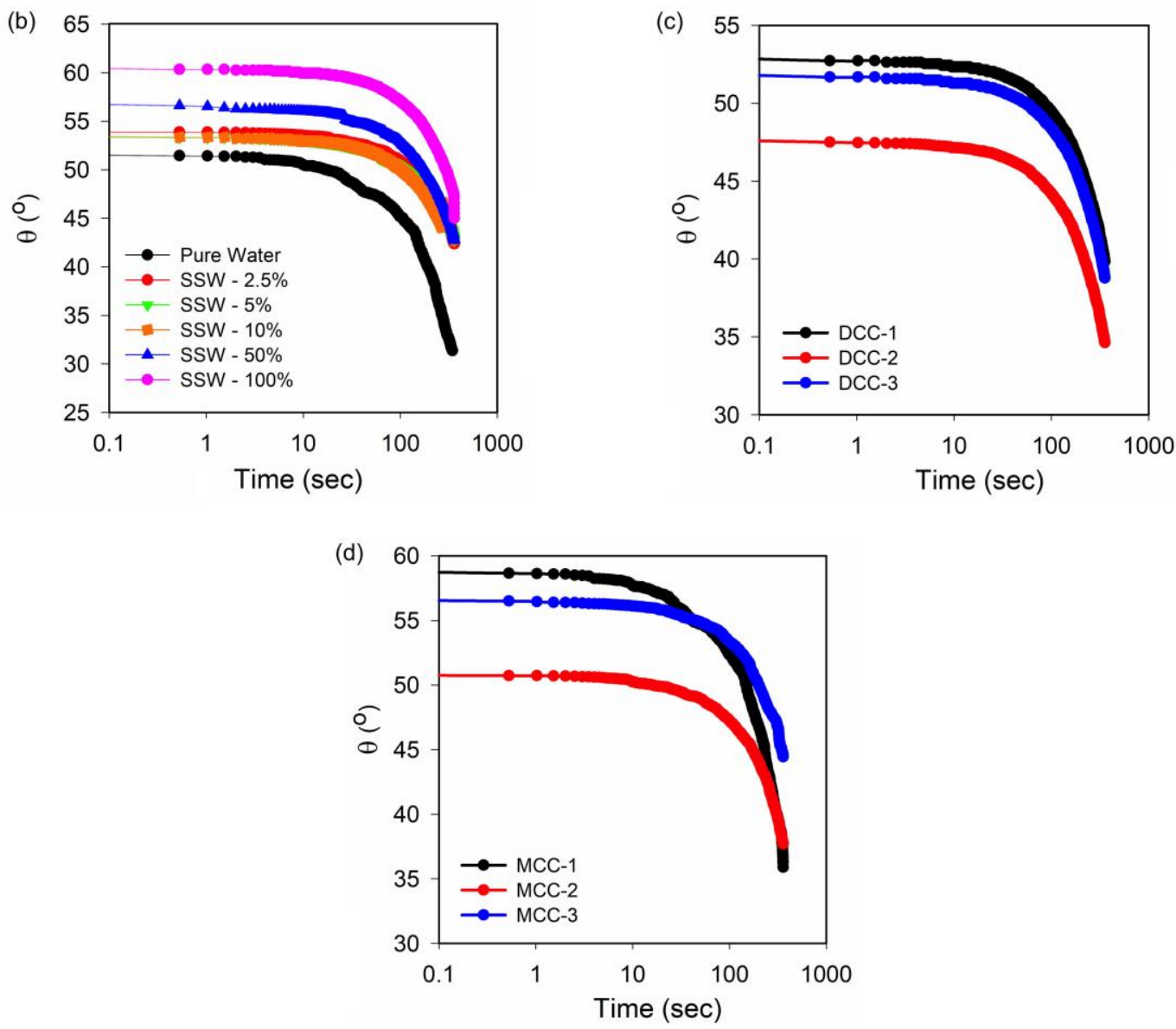

Figure 9. Photographic images (a) of brine droplets on glass substrates and the resulting dynamic contact angle for (b) varying salinity (SSW), (c) varying divalent cation concentration (MCC), and (d) varying monovalent cation concentration (DCC). The highest standard error for the measurement is $\pm 2^{\circ}$.

The contact angles of the surfactant-brine solutions on the glass substrate are shown in Figure 10. As can be seen from the data, the presence of $\mathrm{iC}_{18} \mathrm{~S}(\mathrm{FO}-180)$ lower contact angle values significantly compared to brine solutions alone. This is due the better synergistic effect between surfactant monomers in brine solutions with glass substrate. ${ }^{41}$ Spreading of surfactant-brine droplets on the substrate decreased the $\theta$ values and consequently led to more wettability alteration 
on the substrate (from oil-wet to water-wet). This could explain why wettability alteration is a promising scenario in oil movement through the reservoirs. The highest and lowest $\theta$ values were obtained for SSW-100\% and SSW-5\%, respectively. In SSW series, increasing brine concentrations led to increase in the contact angle of the surfactant solution on the glass substrates from $10^{\circ}$ to $51^{\circ}$. The final $\theta$ values after $1200 \mathrm{~s}$ reached to $8^{\circ}$ and $39^{\circ}$ for SSW $2.5 \%$ and $100 \%$, respectively. Decrease in polarity between the hydrophobic tail and head in surfactant after adding brine $^{25}$ led to further increase in contact angles. ${ }^{43}$

Combination of surfactant and brine solutions in lower concentrations (SSW-2.5\%, SSW-5\%) indicates significant spreading (more wettability alteration) than higher ionic solutions on the substrate. The hydrophilic behavior of surfactant in lower electrolyte solutions was determined by decrease in binding affinities between negatively surface charges and surfactant molecules and results confirmed by surface tension and IFT analysis. Also, the lower surface energy of branched surfactant promotes a decrease in $\theta$, and act as a useful parameter in the rock wettability alteration.

Figure 10c and d shows the valence effect of cations on $\theta$ values in MCC and DCC solutions. Decreasing $\mathrm{Ca}^{2+}$ and $\mathrm{Mg}^{2+}$ in MCC series (MCC-1 to MCC-3) leads to further increasing $\theta$ in the presence of surfactant. In the presence of high amount of $\mathrm{Ca}^{2+}$ and $\mathrm{Mg}^{2+}$ (MCC-1), negatively charged surface attract the positive ions strongly, hence lower contact angle. On the hand, decreasing divalent cations (MCC-3) lead to reducing chemical binding on the negatively charged surface, which in turn has led to a higher contact angle between the solid substrate and the liquid droplet. Subsequently, the combination of the lower amount of $\mathrm{Ca}^{2+}$ and $\mathrm{Mg}^{2+}$ ions promoted hydrophobicity on the surface resulting in less wettability alteration. DCC series follow the same trend as MCC, however the changes in $\theta$ values are not very notable which shows monovalent ions $\left(\mathrm{Na}^{+}\right.$and $\left.\mathrm{K}^{+}\right)$do not significantly affect the wettability alteration compared to divalent ions. 

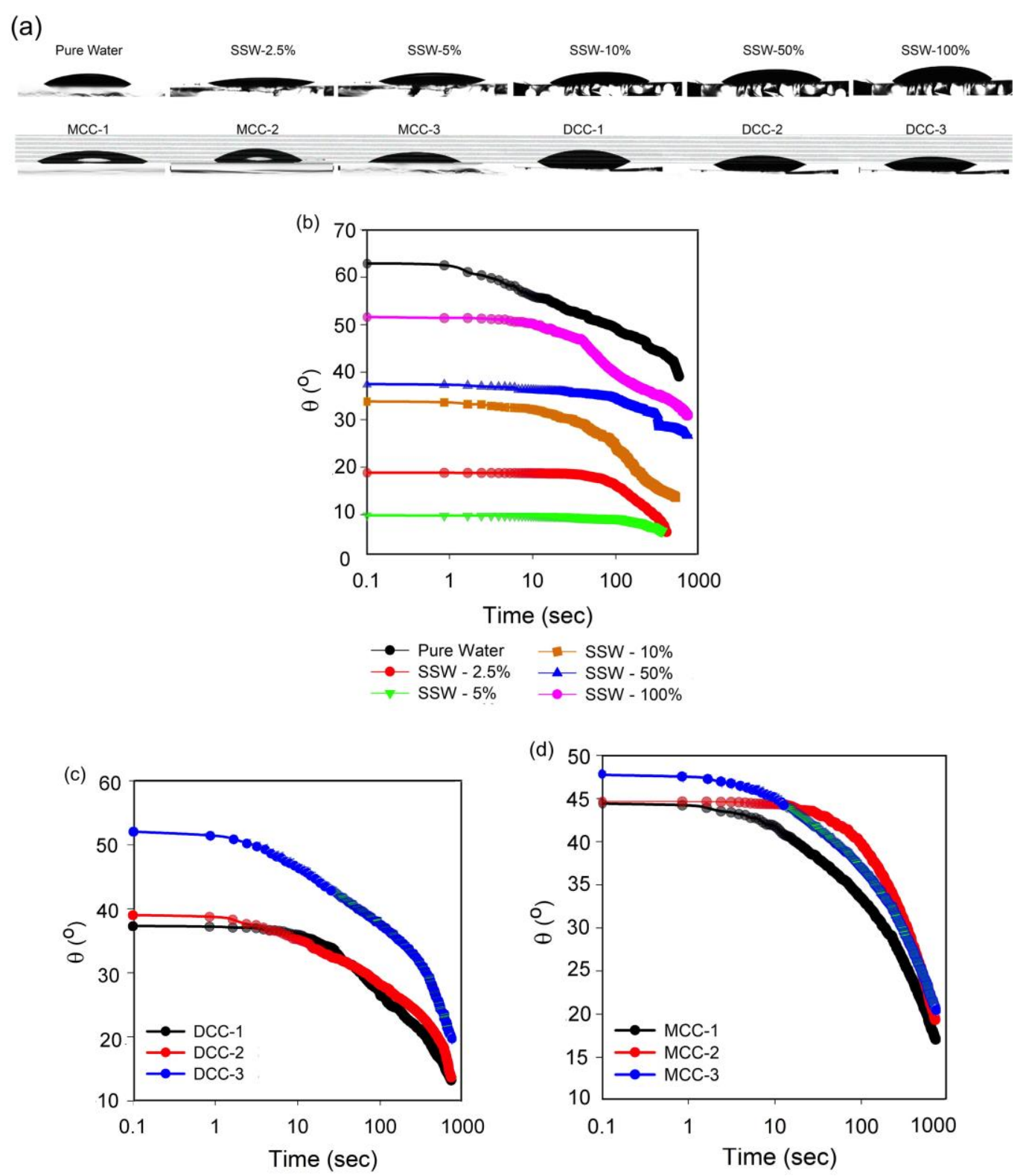

Figure 10. Photographic images (a) of surfactant-brine droplets on glass substrates and the resulting dynamic contact angle for (b) varying salinity (SSW), (c) varying divalent cation concentration (MCC), and (d) varying monovalent cation concentration (DCC). The highest standard error for the measurement is $\pm 2^{\circ}$. 
Oil Recovery Factors using the Microfluidic Apparatus. Oil recovery factors of pure brine solutions at different salt concentrations in heterogeneous microfluidic pattern are shown in Figure 11. Due to the asymmetric distribution of pores (geometry) and repulsion forces along the heterogeneous pattern, fluid instability (viscous fingering) can be more expected after each flooding (see below). The highest oil recovery values were observed for the medium brine solutions (SSW-2.5\% and SSW-10\%) as is shown in Figure 11a.

As can be seen from the data in Figure 11a, only 25\% oil recovery is achieved by pure water; however, upon addition of salts the oil recovery increases to maximum 35\% for 5\% brine concentration $(\mathrm{PV} \sim 1)$. Such a brine molar ratio dependency of these recoveries is surprising, but these values can be rationalized along pattern on the basis of intermolecular interactions between oil-brine water-substrate. Therefore, for the higher brine solutions (SSW-50\% and SSW-100\%), strong attractive ionic interactions between oil-brine-substrate are dominant over further recovery values and the oil recovery reduces to around $20 \%$. The cation exchange is one of the predominant mechanism in low salinity flooding in sandstone reservoirs. ${ }^{44}$ The cation exchange mechanism causes the oil to move towards the outlet by charge transferring between brines and the solid substrate. Similarly, $\sim 1$ PV brine solution flooding, the highest oil recovery factors were determined by MCC-3 and DCC-3. 

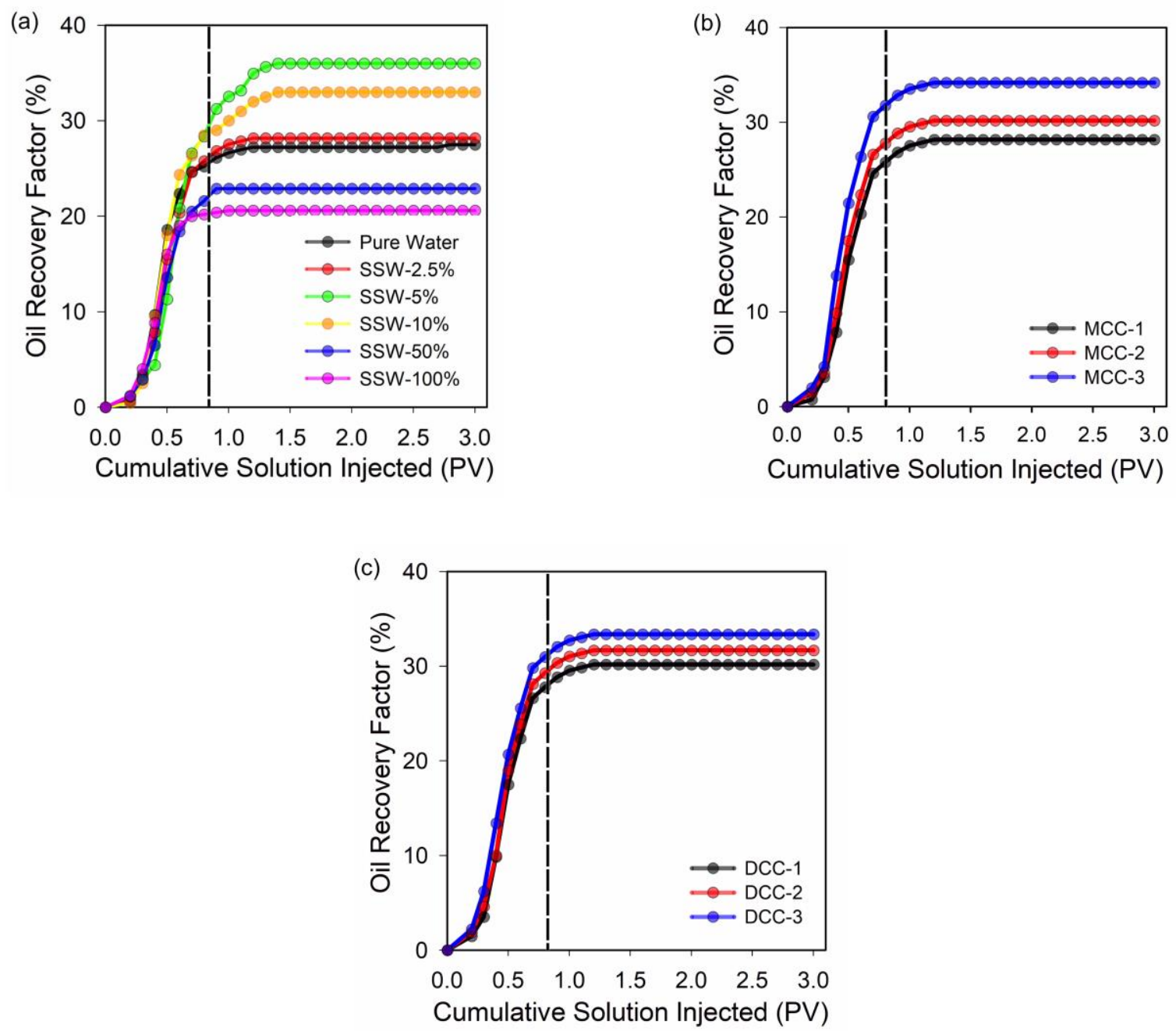

Figure 11. Oil recovery factors in pure brine solution using a heterogeneous pattern of glass micromodel for (a) SSW series with the increase of brine concentration from SSW-2.5\% to SSW$100 \%$, (b) MCC at varying divalent cation concentrations, and (c) DCC at varying monovalent cation concentrations.

In the MCC and DCC series studied here, flooding with higher concentrations of divalent cation (MCC-1) leads to higher adsorption of cations on the surface, which causes lower oil recovery efficiency on the oil-brine-glass systems. Increase in oil recovery by MCC-3 solution is due to the multi-component ion exchange (MIE) mechanism, ${ }^{45}$ where the minimum amount of $\mathrm{Ca}^{2+}, \mathrm{Mg}^{2+}$ divalent cations overcome chemical binding between negatively charged solid substrate and oil 
component. Another notable feature is no significant differences in oil recovery values for DCC systems as it was also observed by adsorption and contact angle measurements. In summary the presence of divalent cations in brine solutions led to the promoting electrostatic forces, while the presence of monovalent cations caused the repulsive electrostatic forces. ${ }^{41}$

Oil recovery factors for surfactant-brine solutions (SSW series) are shown in Figure 12. Figure 12a shows how manipulating surfactants per counter ion species evolves with the designed brine aqueous solutions under the assumption of double layer expansion (DLE) and MIE mechanism. The oil recoveries data in Figure 12a imply that a similar recovery was obtained up to a PV of $\sim 0.5$; however, as the PV increased from 0.5 to 0.9 , there is a shift in oil recovery by increasing the brine solutions. Figure 12a indicates that after $\sim 0.9 \mathrm{PV}$, the highest oil recovery factor $(71 \%)$ was obtained by surfactant in brine SSW-5\% solution and this was an increase of 36\% from the pure SSW-5\%. The main reason for this behavior is coming from two phenomena on the solidliquid substrate; DLE and MIE, where the interactions between brine-surfactant-rock at certain concentration caused more wettability alteration in sandstone reservoirs. ${ }^{45}$ The data in Figure $12 \mathrm{~b}$ for MCC solutions indicate that decreasing $\mathrm{Ca}^{2+}$ and $\mathrm{Mg}^{2+}$ concentration has an improving effect on the oil recovery possible due to the lower adsorption on the substrate. Decreasing the divalent cation concentration enhances the recovery factor of $66 \%$ to $72 \%$ for MCC- 1 and MCC-3, respectively. As can be observed from Figure 12c, the recovery factors in DCC-1, DCC-2, and DCC-3 are $66 \%, 67 \%$, and $69 \%$, respectively. Based on the oil recovery experiments, contact angle and adsorption measurements in DCC solutions, it can be concluded that the reduction of monovalent cation concentration doesn't have significant role in changing surface wettability and therefore improving the oil recovery. 

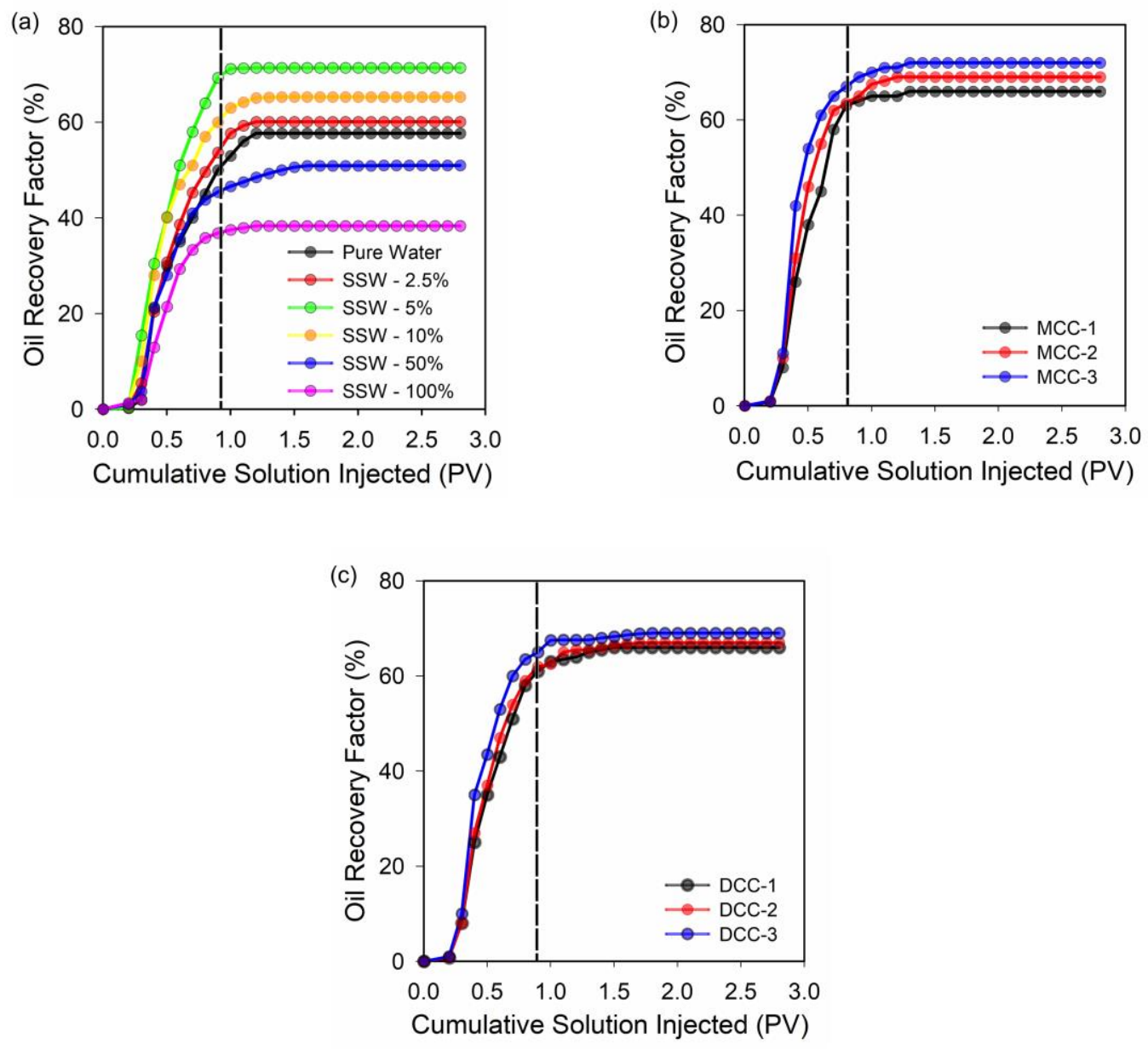

Figure 12. Oil recovery factors in $\mathrm{iC}_{18} \mathrm{~S}$ (FO-180)-brine solution using a heterogeneous glass micromodel for (a) SSW series with the increase of brine concentration from SSW-2.5\% to SSW$100 \%$, (b) MCC at varying divalent cation concentrations, and (c) DCC at varying monovalent cation concentrations.

The images taken from the micromodel after the solution flooding of the pure brine, pure surfactant and surfactant-brine are shown in Figure 13. Figure 13a implies that the brine flooding (SSW-5\%, maximum brine recovery) could not create a homogeneous solution front in order to mobilize residual oil. Consequently, it causes further flow channeling along the microchannel and oil performs like a dam in front of the injected fluid. The main reason for this behavior is due to the relatively low viscosity of the brine solution and strong interaction between oil-brine solution- 
substrate. ${ }^{30}$ In contrast, as shown in Figure $13 \mathrm{~b}$, oil deformed by a homogenous $\mathrm{iC}_{18} \mathrm{~S}(\mathrm{FO}-180)$ solution with further moving displacement front. This is a consequence of the balance among wettability alteration, adhesion force, the interaction between the head charge and substrate surface charges, and cation exchange mechanism in a saturate environment. ${ }^{27}$ For the $\mathrm{iC}_{18} \mathrm{~S}(\mathrm{FO}-180)$ SSW-5\% solutions, the surfactant is more hydrophilic when contacting residual oil, causing improved and homogenous surfactant movements. Upon wetting in $\mathrm{iC}_{18} \mathrm{~S}(\mathrm{FO}-180)$-brine solution (Figure 13c), the LSES molecules can embed themselves among the adhered oil and the glass substrate. Furthermore, cation exchange mechanism promotes the contact between polar heads and surface, and oil efficiently separates from the negatively charged surfaces because of the low adhesion on the substrate. As a result, it appears that the presence of a define amount of brine species with the surfactant reduces ion-pair forms by diffusion of surfactant on the substrate as well as decreasing contact angles on the substrate. ${ }^{27}$
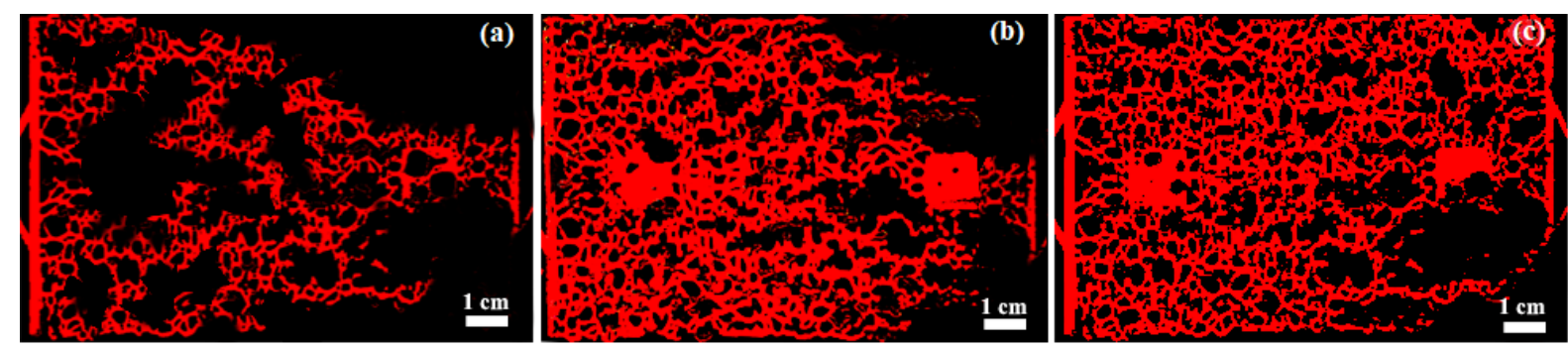

Figure 13. Colorized images taken from the micromodel after the solution flooding of (a) pure brine SSW-5\%, (b) $\mathrm{iC}_{18} \mathrm{~S}(\mathrm{FO}-180)$ at $\mathrm{CMC}$, and (c) $\mathrm{iC}_{18} \mathrm{~S}(\mathrm{FO}-180)-$ brine $\mathrm{SSW}-5 \%$.

A range of oil displacement mechanisms with surfactant have been proposed in the literature, including: decreasing oil-water IFT $^{43}$ rock surface wettability alteration, ${ }^{30,45}$ and creation of structural disjoining pressure in the pores. ${ }^{47}$ Based upon our results we believe that the "wettability alteration" mechanism is the most relevant for $\mathrm{iC}_{18} \mathrm{~S}(\mathrm{FO}-180)$ under simulated reservoir conditions. The proposed mechanism (Figure 14) shows the effect of LSES solutions in oil 
displacement that is consistent with experimental measurement during LSES flooding. At $\mathrm{t}=\mathrm{t}_{0}$ surfactant micelles have diffused into the pores and caused changes to equilibrium in oil-brinesubstrate system. At $\mathrm{t}=\mathrm{t}_{0}+\Delta \mathrm{t}$ (Figure $14 \mathrm{~b}$ ), micelles are in equilibrium with the system causing more interactions between surfactants and oils, as well as dominance over strong chemical bonding in fluid-fluid and fluid-substrate interface. Further surfactant flooding from $t_{0}$ to $\left(t_{0}+\Delta t\right)$ (Figure 14c) leads to further surfactant diffusion into the interface and release entrapped oil and higher oil mobility ratio. As a result, successful operational surfactant-brine flooding is observed for the branched surfactant, $\mathrm{iC}_{18} \mathrm{~S}(\mathrm{FO}-180)$.
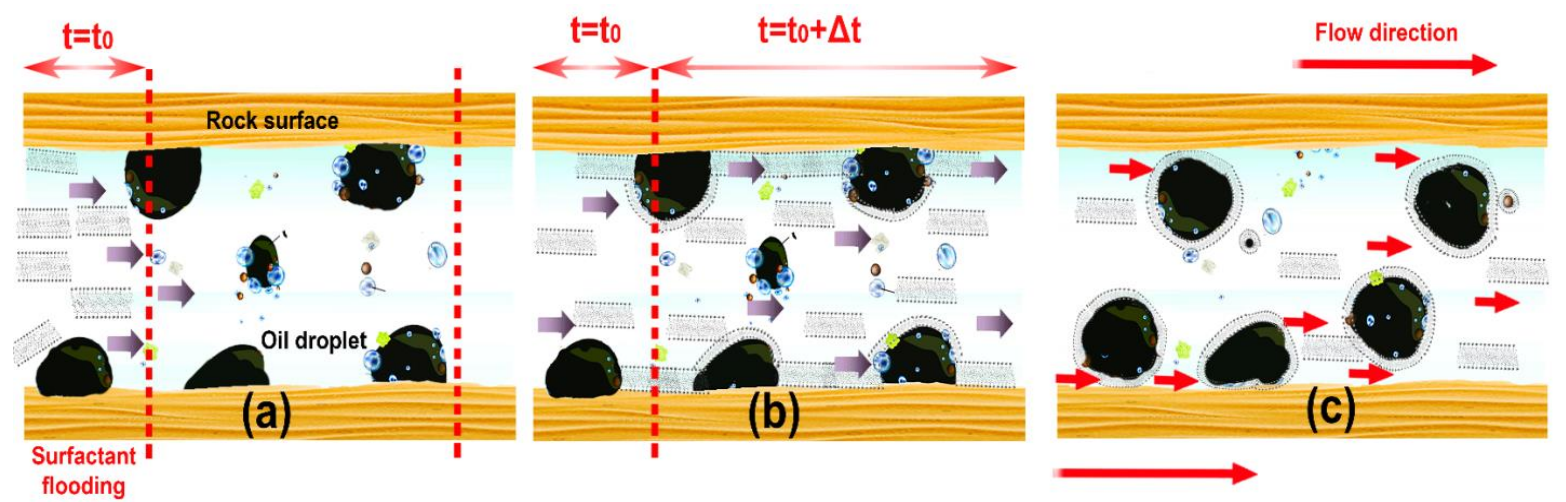

Figure 14. Schematic model representation of the mechanism by which $\mathrm{iC}_{18} \mathrm{~S}$ (FO-180)-brine flooding that lead to the wettability alteration and oil recovery.

\section{CONCLUSIONS}

Herein we report the first study of oil recovery using a microfluidic pattern using a highly branched anionic surfactant in low to high brine solutions. The easily prepared surfactant, $\mathrm{iC}_{18} \mathrm{~S}(\mathrm{FO}-180)$, decreases surface tension, IFT, and contact angles, as well as altering the wettability of the glass substrate (oil-wet to water-wet). Surface tension $\left(\sim 25 \mathrm{mN} \cdot \mathrm{m}^{-1}\right)$, IFT, and $\theta$ values at $\mathrm{CMC}$ showing a significant synergistic effect between air-fluid, fluid-fluid, and rockfluid, respectively. Furthermore, through rheology measurements, surfactant in brine solution has 
shown thinning behavior that could be performed at different operational condition in the reservoirs. Also, surfactant adsorption on the crushed glasses was negligible, allowing more waterwet condition and minimum loss on the substrate. We found that under low salinity conditions addition of $\mathrm{iC}_{18} \mathrm{~S}(\mathrm{FO}-180)$ results in increased water-wetting, which in turn is ideal for improved oil recovery. Recovery factor analysis showed that surfactants boosting oil sweeping in comparison with pure brine solution. The maximum oil recovery $(72 \%)$, obtained in low salinity surfactant-brine flooding, was an impressive for a single surfactant system. We therefore expect the derivations of this new class of branched surfactant to open up potential application in industrial areas including $\mathrm{CO}_{2}$-EOR, emulsification, polymer, and ASP flooding.

\section{ASSOCIATED CONTENT}

\section{Supporting Information.}

The Supporting Information is available free of charge on the ACS Publications website at DOI: XXXXXX. Composition and characterization of brine and brine-surfactant solutions; images of surfactant solutions in different brine series; electrical conductivity of surfactant-brine solutions; droplet size of brine and surfactant-brine solutions in n-decane; zeta potential measurements in the presence of different salt solutions; time-dependence of shear rate-shear stress of brine solutions; static IFT of surfactant and brine solutions at different temperature; the effect of brine on LSEM surfactants.

\section{AUTHOR INFORMATION}

\section{Corresponding Author}

*E-mail: (S.A.) s.alexander@swansea.ac.uk; (A.R.B.) a.r.barron@swansea.ac.uk; arb@rice.edu. ORCHID 
Shirin Alexander: 0000-0002-4404-0026

Masanobu Sagisaka: $\underline{0000-0001-9685-7524}$

Andrew R. Barron: 0000-0002-2018-8288

\section{Notes}

The authors declare no competing financial interest.

\section{ACKNOWLEDGMENT}

Financial support was provided by the Welsh Government Sêr Cymru Programme through Sêr Cymru II Welsh Fellowship part funded by the European Regional Development Fund (ERDF) (S.A.), the Sêr Cymru Chair for Low Carbon Energy and Environment (A.R.B.), the Sêr Cymru National Research Network in Advanced Engineering and Materials (NRN-141), King Saud University (under the $\mathrm{K}(\mathrm{SU})^{2}$ program), and Flexible Integrated Energy Systems (FLEXIS) operations funded by the Welsh European Funding Office (WEFO) through the Welsh Government. The Robert A. Welch Foundation (C-0002) is acknowledged for additional support (A.R.B.). STFC is acknowledged for allocation of SANS beam time, and travel funding. Christopher Hill (University of Bristol, UK) is thanked for his assistance during the SANS experiment.

\section{NOMENCLATURE}

$\mathrm{AES}=$ alkyl ethoxy sulfate

$\mathrm{ASG}=$ alkyl sulfate gemini

$\mathrm{CMC}=$ critical micelle concentration

$\mathrm{DCC}=$ divalent cationic constant

$\mathrm{DCM}=$ dichloromethane

DLE $=$ double layer expansion 
DLS = dynamic light scattering

$\mathrm{EOR}=$ enhanced oil recovery

GAS $=$ Guerbet alkoxy sulfate

HPHT $=$ high pressure high temperature

IFT $=$ interfacial tension

LSES $=$ low surface energy surfactant

$\mathrm{MCC}=$ monovalent cation constant

MIE $=$ multi-component ion exchange

$\mathrm{PV}=$ pore volume

SANS $=$ small-angle neutron scattering

$\mathrm{SSW}=$ sea salt water

TMS $=$ tetramethylsilane

TSP $=$ tristyrylphenol

\section{REFERENCES}

(1) Shah, D. O.; Schechter, R. S. Improved Oil Recovery by Surfactant and Polymer Flooding, Academic Press, New York, 1977.

(2) Khanamiri, H. H.; Nourani, M.; Tichelkamp, T.; Stensen, J. Å.; Øye, G.; Torsæter, O. Lowsalinity-surfactant enhanced oil recovery (EOR) with a new surfactant blend: effect of calcium cations. Energy Fuels 2016, 30, 984-991.

(3) Cheraghian, G.; Kiani, S.; Nassar, N. N.; Alexander, S.; Barron, A. R. Silica nanoparticle enhancement in the efficiency of surfactant flooding of heavy oil in a glass micromodel. Ind. Eng. Chem. Res. 2017, 56, 8528-8534. 
(4) Dai, C.; Wang, K.; Liu, Y.; Li, H.; Wei, Z.; Zhao, M. Reutilization of fracturing flowback fluids in surfactant flooding for enhanced oil recovery. Energy Fuels 2015, 29, 2304-2311.

(5) Salehi, M.; Johnson, S. J.; Liang, J.-T. Mechanistic study of wettability alteration using surfactants with applications in naturally fractured reservoirs. Langmuir 2008, 24, 14099-14107.

(6) Alagic, E.; Skauge, A. Combined low salinity brine injection and surfactant flooding in mixed- wet sandstone cores. Energy Fuels 2010, 24, 3551-3559.

(7) Hirasaki, G. J.; Miller, C. A.; Puerto, M. Recent Advances in Surfactant EOR, SPE Annual Technical Conference and Exhibition, Denver, Colorado, USA, Society of Petroleum Engineers, 2008, SPE-115386-MS.

(8) Morvan, M.; Koetitz, R.; Moreau, P.; Pavageau, B.; Rivoal, P.; Roux, B. A combinatorial approach for identification of performance EOR surfactants, SPE Symposium on Improved Oil Recovery, SPE Symposium on Improved Oil Recovery, Tulsa, Oklahoma, Society of Petroleum Engineers 2008, SPE-113705-MS

(9) Sharma, M. M.; Gao, B. Salt-tolerant anionic surfactant compositions for enhanced oil recovery (EOR) applications. Patent Application, WO2014055158A1, 2014.

(10) Adkins, S.; Arachchilage, P.; Gayani, W.; Solairaj, S.; Lu, J.; Weerasooriya, U.; Pope, G. A. Development of thermally and chemically stable large-hydrophobe alkoxy carboxylate surfactants, SPE Improved Oil Recovery Symposium, Tulsa, Oklahoma, USA, Society of Petroleum Engineers, 2012, SPE-154256-MS.

(11) Gao, B.; Sharma, M. M. A family of alkyl sulfate gemini surfactants. 2. Water-oil interfacial tension reduction. J. Colloid Interface Sci. 2013, 407, 375-381. 
(12) Liyanage, P. J.; Solairaj, S.; Pinnawala Arachchilage, G.; Linnemeyer, H. C.; Kim, D. H.; Weerasooriya, U.; Pope, G. A. Alkaline surfactant polymer flooding using a novel class of large hydrophobe surfactants, SPE Improved Oil Recovery Symposium, Tulsa, Oklahoma, USA, Society of Petroleum Engineers, 2012, SPE-154274-MS.

(13) Aoudia, M.; Al-Shibli, M. N.; Al-Kasimi, L. H.; Al-Maamari, R.; Al-Bemani, A. Novel surfactants for ultralow interfacial tension in a wide range of surfactant concentration and temperature. J. Surfactants Deterg. 2006, 9, 287-293.

(14) Liyanage, P. J.; Lu, J.; Arachchilage, G. W. P.; Weerasooriya, U. P.; Pope, G. A. A novel class of large-hydrophobe tristyrylphenol (TSP) alkoxy sulfate surfactants for chemical enhanced oil recovery. J. Petrol. Sci. Eng. 2015, 128, 73-85.

(15) Levitt, D.; Jackson, A.; Heinson, C.; Britton, L. N.; Malik, T.; Dwarakanath, V.; Pope, G. A. Identification and evaluation of high-performance EOR surfactants, SPE Reserv. Eval. Eng. 2006, 12, SPE-100089-PA.

(16) Levitt, D.; Dufour, S.; Pope, G. A.; Morel, D. C.; Gauer, P. R. Design of an ASP flood in a high-temperature, high-salinity, low-permeability carbonate, International Petroleum Technology Conference, 2011, IPTC-14915-MS.

(17) Alexander, S.; Smith, G. N.; James, C.; Rogers, S. E.; Guittard, F.; Sagisaka, M.; Eastoe, J. Low-surface energy surfactants with branched hydrocarbon architectures. Langmuir 2014, 30, 3413-3421. 
(18) Alexander, S.; Eastoe, J.; Lord, A. M.; Guittard, F.; Barron, A. R. Branched hydrocarbon low surface energy materials (LSEMs) for superhydrophobic nanoparticle derived surfaces. $A C S$ Appl. Mater. Interfaces 2016, 8, 660-666.

(19) Al-Shatty, W.; Lord, A. M.; Alexander, S.; Barron, A. R. Tunable surface properties of aluminum oxide nanoparticle from highly hydrophobic to highly hydrophilic. ACS Omega 2017, $2,2507-2514$.

(20) Sagisaka, M.; Narumi, T.; Niwase, M.; Narita, S.; Ohata, A.; James, C.; Yoshizawa, A.; Taffin de Givenchy, E.; Guittard, F.; Alexander, S.; Eastoe, J. Hyperbranched hydrocarbon surfactants give fluorocarbon-like low surface energies. Langmuir 2014, 30, 6057-6063.

(21) Szlendak, S. M.; Nguyen, N. M.; Nguyen, Q. P. Laboratory investigation of low-tensiongas flooding for improved oil recovery in tight formations. SPE J. 2013, 18, 851-866.

(22) Ahmadi, M. A.; Shadizadeh, S. R. Spotlight on the new natural surfactant flooding in carbonate rock samples in low salinity condition. Sci. Rep. 2018, 8, 10985.

(23) Barnes, H. A.; Hutton, J. F.; Walters, K. An Introduction to Rheology, Volume 3. Elsevier, The Netherlands, 1989.

(24) Arnold, O.; Bilheux, J. C.; Borreguero, J. M.; Buts, A.; Campbell, S. I.; Chapon, L.; Doucet, M; Draper, N.; Ferraz Leal, R.; Gigg, M. A.; Lynch, V. E.; Markvardsen, A.; Mikkelson, D. J.; Mikkelson, R. L.; Miller, R.; Palmen, K.; Parker, P.; Passos, G.; Perring, T. G.; Peterson, P. F.; Ren, S.; Reuter, M. A.; Savici, A. T.; Taylor, J. W.; Taylor, R. J.; Tolchenov, R.; Zhou, W.; Zikovsky, J. Mantid-Data analysis and visualization package for neutron scattering and SR experiments, Nucl. Instrum. Methods Phys. Res. A 2014, 764, 156-166. 
(25) Rosen, M. J.; Kunjappu, J. T. Surfactants and Interfacial Phenomena. John Wiley \& Sons, New Jersey, 2012.

(26) Ren, Z. H., Mechanism of the salt effect on micellization of an aminosulfonate amphoteric surfactant. Ind. Eng. Chem. Res. 2015, 54, 9683-9688.

(27) Moeini, F.; Hemmati-Sarapardeh, A.; Ghazanfari, M.-H.; Masihi, M.; Ayatollahi, S. Toward mechanistic understanding of heavy crude oil/brine interfacial tension: The roles of salinity, temperature and pressure. Fluid Ph. Equilibria 2014, 375, 191-200.

(28) Kumar, S.; Mandal, A. Studies on interfacial behavior and wettability change phenomena by ionic and nonionic surfactants in presence of alkalis and salt for enhanced oil recovery. Appl. Surf. Sci. 2016, 372, 42-51.

(29) Sofla, S. J. D.; Sharifi, M.; Sarapardeh, A. H. Toward mechanistic understanding of natural surfactant flooding in enhanced oil recovery processes: the role of salinity, surfactant concentration and rock type. J. Mol. Liq. 2016, 222, 632-639.

(30) Yu, D.; Huang, X.; Deng, M.; Lin, Y.; Jiang, L.; Huang, J.; Wang, Y. Effects of inorganic and organic salts on aggregation behavior of cationic gemini surfactants. J. Phys. Chem. B 2010, $114,14955-14964$.

(31) Miller, C. A.; Ghosh, O.; Benton, W. J. Behavior of dilute lamellar liquid-crystalline phases. Colloids Surf. 1986, 19, 197-223.

(32) Liu, C. K.; Warr, G. G. Self-assembly of didodecyldimethylammonium surfactants modulated by multivalent, hydrolyzable counterions. Langmuir 2015, 31, 2936-2945. 
(33) Kumar, S.; Khan, Z. A. Micellar association in simultaneous presence of organic salts/additives. J. Surfactants Deterg. 2002, 5, 55-59.

(34) Aswal, V.; Goyal, P.; Thiyagarajan, P. Small-angle neutron-scattering and viscosity studies of CTAB/NaSal viscoelastic micellar solutions. J. Phys. Chem. B 1998, 102, 2469-2473.

(35) Sharma, A. K.; Tiwari, A. K.; Dixit, A. R. Rheological behaviour of nanofluids: a review. Renew. Sust. Energy Rev. 2016, 53, 779-791.

(36) Karimi, M.; Al-Maamari, R. S.; Ayatollahi, S.; Mehranbod, N. Impact of sulfate ions on wettability alteration of oil-wet calcite in the absence and presence of cationic surfactant. Energy Fuels 2016, 30, 819-829.

(37) Alvarez, J. O.; Saputra, I. W. R.; Schechter, D. S. Potential of improving oil recovery with surfactant additives to completion fluids for the Bakken. Energy Fuels 2017, 31, 5982-5994.

(38) Son, H. A.; Choi, S. K.; Jeong, E. S.; Kim, B.; Kim, H. T.; Sung, W. M.; Kim, J. W. Microbial activation of Bacillus subtilis-immobilized microgel particles for enhanced oil recovery. Langmuir 2016, 32, 8909-8915.

(39) Ahmadi, M. A.; Shadizadeh, S. R. Adsorption of novel nonionic surfactant and particles mixture in carbonates: enhanced oil recovery implication. Energy Fuels 2012, 26, 4655-4663.

(40) Jian, G.; Puerto, M. C.; Wehowsky, A.; Dong, P.; Johnston, K. P.; Hirasaki, G. J.; Biswal, S. L. Static adsorption of an ethoxylated nonionic surfactant on carbonate minerals. Langmuir 2016, 32, 10244-10252. 
(41) Haagh, M. E. J.; Sîretanu, I.; Duits, M.; Mugele, F., Salinity-dependent contact angle alteration in oil/brine/silicate systems: the critical role of divalent cations. Langmuir 2017, 33, 3349-3357.

(42) Price, L. C. Aqueous solubility of petroleum as applied to its origin and primary migration. AAPG Bulletin 1976, 60, 213-244.

(43) Qu, D.; Suter, R.; Garoff, S. Surfactant self-assemblies controlling spontaneous dewetting. Langmuir 2002, 18, 1649-1654.

(44) Brady, P. V.; Morrow, N. R.; Fogden, A.; Deniz, V.; Loahardjo, N. Electrostatics and the low salinity effect in sandstone reservoirs. Energy Fuels 2015, 29, 666-677.

(45) Pouryousefy, E.; Xie, Q.; Saeedi, A. Effect of multi-component ions exchange on low salinity EOR: coupled geochemical simulation study. Petroleum 2016, 2, 215-224.

(46) Hilner, E.; Andersson, M. P.; Hassenkam, T.; Matthiesen, J.; Salino, P.; Stipp, S. L. S. The effect of ionic strength on oil adhesion in sandstone-the search for the low salinity mechanism. Sci. Rep. 2015, 5, 9933.

(47) Tang, G.-Q.; Morrow, N. R. Influence of brine composition and fines migration on crude oil/brine/rock interactions and oil recovery. J. Petrol. Sci. Eng. 1999, 24, 99-111. 
Submitted to Energy \& Fuels

\section{Graphical Abstract}
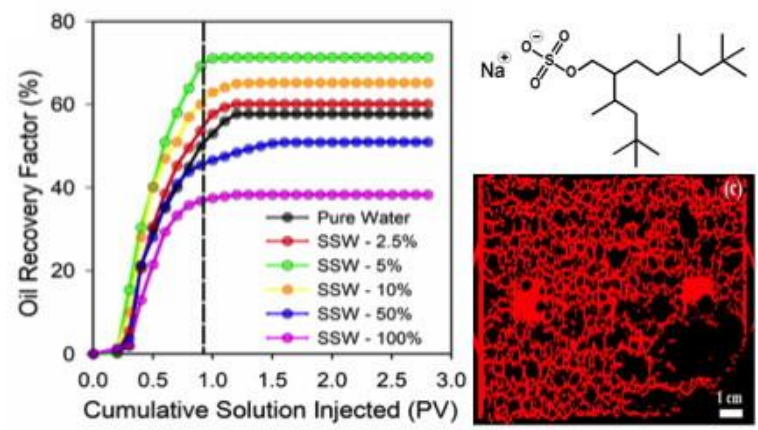